\title{
Experimental and theoretical investigation of tunable picosecond pulse generation in longitudinally pumped dye laser generators and amplifiers
}

\author{
P. SPERBER, W. SPANGLER, B. MEIER, A. PENZKOFER \\ Naturwissenschaftliche Fakultät II - Physik Universität Regensburg, \\ 8400 Regensburg, FRG
}

Received 2 March; accepted 21 April 1988

Picosecond pulse generation in longitudinally pumped dye laser generators and amplifiers is studied experimentally and theoretically. Frequency-tunable pulses between 720 and $940 \mathrm{~nm}$ are generated with a picosecond ruby laser pump source. The amplification of spontaneous emission and of seeding pulses in the generator and amplifier cells is investigated. Stimulated emission cross-sections and excited-state absorption cross-sections are determined by computer simulations. The coherence properties of the generated radiation are analysed. Resonance Raman contributions are resolved.

\section{Introduction}

Frequency-tunable picosecond light pulses may be generated in mode-locked dye laser oscillators [1-3], in distributed feedback dye lasers [4], in dye laser generators [5-10] and in parametric generators [11-13]. Pulsed dye laser amplifiers [14-16] and parametric amplifiers $[11,12]$ are used to raise the laser signals to high power levels.

In this paper intense frequency-tunable picosecond light pulses in the spectral region between 720 and $940 \mathrm{~nm}$ are generated in picosecond laser pumped dye cells. Either the fluorescence light is amplified (amplified spontaneous emission, ASE [17]) or weak, parametrically generated light continua [18] are amplified [19] (seeding pulse amplification, SPA [20]). Single picosecond light pulses of a passively mode-locked ruby laser are used as the pump source. The amplification of fluorescence light starts in a longitudinally pumped dye cell (laser generator) and is continued in a series of longitudinally pumped dye cells (laser amplifiers). The picosecond light continuum is generated in the ruby laser amplifier by parametric four-photon interaction.

\section{Dyes}

The experiments were performed with six different dyes in the spectral region between 720 and $940 \mathrm{~nm}$. The relevant spectroscopic data of the dyes are listed in Table I. The groundstate absorption cross-section spectra, the $\mathrm{S}_{1}-\mathrm{S}_{0}$ stimulated emission cross-section spectra, and $S_{1}-S_{n}$ excited state absorption cross-section data are presented in Figs 1 to 6 for the dyes 
TABLE I Generator-amplifier parameters. Length of generator and amplifier cells are $l=1 \mathrm{~cm}$. For parameters see Fig. 23. Pump laser: wavelength $\lambda_{\mathrm{L}}=694.3 \mathrm{~nm}$, pulse duration $\Delta t_{\mathrm{L}}=30 \mathrm{ps}$, pump pulse diameter $d=0.8 \mathrm{~mm}$. Observation angle $\Delta \Theta^{\prime}=6^{\circ}$

\begin{tabular}{|c|c|c|c|c|c|c|}
\hline & \multicolumn{6}{|l|}{ Dye/solvent } \\
\hline & DDI/ME & $\mathrm{Rh} 800 / \mathrm{ME}$ & HITCI/ME & HDITCI/EG-DMSO & Styril 9/DMSO & IR 140/EG-DMSO \\
\hline$\sigma_{\mathrm{L}}\left(\mathrm{cm}^{2}\right)$ & $7.6 \times 10^{-16}$ & $2.65 \times 10^{-16 *}$ & $3.1 \times 10^{-16}$ & $2.2 \times 10^{-16}$ & $3.9 \times 10^{-17}$ & $1.15 \times 10^{-16}$ \\
\hline$\sigma_{\mathrm{ex}}^{\mathrm{L}}\left(\mathrm{cm}^{2}\right)$ & $(5+1) \times 10^{-17}$ & $(8 \pm 2) \times 10^{-17}$ & $(8.5 \pm 2) \times 10^{-17}$ & $(8.5 \pm 1.5) \times 10^{-17}$ & $(6 \pm 1) \times 10^{-17}$ & $(1.15 \pm 0.25) \times 10^{-16}$ \\
\hline$\sigma_{\mathrm{ex}}^{\mathrm{GEN}}\left(\mathrm{cm}^{2}\right)$ & $(6 \pm 2) \times 10^{-17}$ & $(1.3 \pm 0.5) \times 10^{-17}$ & $(1.3 \pm 0.3) \times 10^{-16}$ & $(1.1 \pm 0.2) \times 10^{-16}$ & $(1.2 \pm 0.5) \times 10^{-16}$ & $(7 \pm 2) \times 10^{-17}$ \\
\hline$\tau_{\mathrm{F}}(\mathrm{ps})$ & $17 \pm 3$ & $540 \pm 70$ & $460 \pm 60$ & $220 \pm 10$ & $390 \pm 40$ & $240 \pm 20$ \\
\hline$\tau_{\mathrm{rad}}(\mathrm{ns})$ & 4.2 & 9.65 & 3.75 & 3.9 & $7.75^{-}$ & 5.1 \\
\hline$q_{\mathrm{F}}$ & 0.004 & 0.16 & 0.12 & 0.057 & 0.05 & 0.047 \\
\hline$\tau_{\mathrm{FC}}^{\dagger}(\mathrm{ps})$ & 0.7 & & 0.7 & 0.7 & 0.7 & 0.7 \\
\hline$\tau_{\mathrm{ex}}^{\mathrm{L}} \ddagger(\mathrm{ps})$ & 0.1 & 0.1 & 0.1 & 0.1 & 0.1 & 0.1 \\
\hline$\tau_{\mathrm{ex}}^{\mathrm{GEN} \ddagger}(\mathrm{ps})$ & 0.1 & 0.1 & 0.1 & 0.1 & 0.1 & 0.1 \\
\hline$\tau_{v}^{\operatorname{GEN} \S}(\mathrm{ps})$ & 4 & 4 & 4 & 4 & 4 & 4 \\
\hline \multicolumn{7}{|c|}{ ASE data for two sets of concentration } \\
\hline Conc. (м) & $10^{-4}$ & $2 \times 10^{-3}$ & $7.7 \times 10^{-5}$ & $5.1 \times 10^{-5}$ & $2.5 \times 10^{-4}$ & $3.7 \times 10^{-5}$ \\
\hline--- & $-\quad--$ & ----- & $----\ldots$ & ----- & $-\quad-\quad-\quad-$ & ----- \\
\hline$\Delta \lambda_{\mathrm{ASE}}(\mathrm{nm})$ & 16 & 40 & 14 & 20 & 32 & 15 \\
\hline$\lambda_{\text {ASE, max }}(\mathrm{nm})$ & 748 & 780 & 788 & 828 & 837 & 868 \\
\hline$\Delta \Theta_{\mathrm{ASE}}(\mathrm{rad})$ & $4.4 \times 10^{-2}$ & $6 \times 10^{-2}$ & $4.4 \times 10^{-2}$ & $4.4 \times 10^{-2}$ & $6 \times 10^{-2}$ & $4 \times 10^{-2}$ \\
\hline$\Delta t_{\mathrm{ASE}}(\mathrm{ps})$ & $24 \pm 5$ & $85 \pm 10$ & $40 \pm 5$ & $35 \pm 5$ & $65 \pm 10$ & $90 \pm 10$ \\
\hline$\Delta \Theta_{\mathrm{AMP}}^{\mathrm{ASE}}(\mathrm{rad})$ & $2.6 \times 10^{-3}$ & $1.7 \times 10^{-3}$ & $2.4 \times 10^{-3}$ & $3 \times 10^{-3}$ & $2.4 \times 10^{-3}$ & $1.9 \times 10^{-3}$ \\
\hline$\Delta t_{\mathrm{AMP}}^{\mathrm{ASE}}(\mathrm{ps})$ & $20 \pm 5$ & $34 \pm 5$ & $24 \pm 5$ & $53 \pm 5$ & $39 \pm 5$ & $32 \pm 5$ \\
\hline Conc. (M) & $2 \times 10^{-4}$ & $5 \times 10^{-4}$ & $5.6 \times 10^{-4}$ & $7.9 \times 10^{-5}$ & & $5 \times 10^{-4}$ \\
\hline--- & ---- & ----- & ------ & ----- & ----- & ----- \\
\hline$\Delta \lambda_{\mathrm{ASE}}(\mathrm{nm})$ & 16 & 15 & 20 & 27 & & 19 \\
\hline$\lambda_{\text {ASE,max }}(\mathrm{nm})$ & 755 & 720 & 813 & 840 & & 895 \\
\hline
\end{tabular}


Seeding pulse amplification data

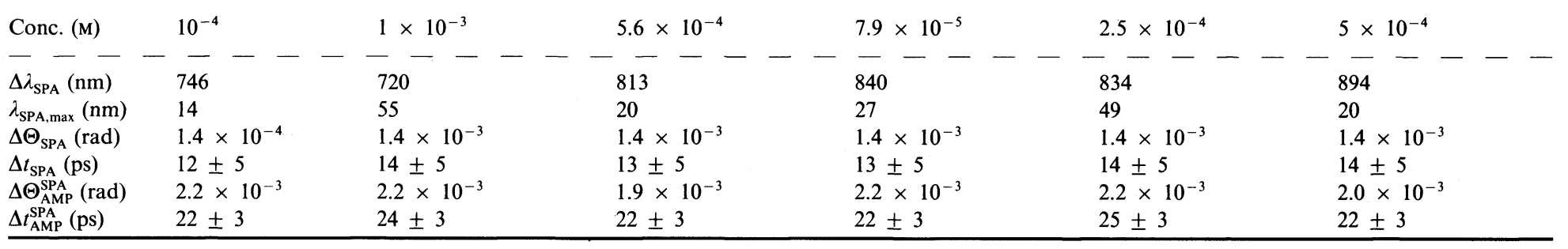

DDI $=1,1^{\prime}$-diethyl-2,2'-dicarbocyanine iodide, Rh800 = rhodamine 800 , HITCI $=1,1^{\prime}, 3,3,3^{\prime}, 3^{\prime}$-hexamethylindotricarbocyanine iodide, HDITCI $=1,1^{\prime}, 3,3,3^{\prime}, 3^{\prime}$ hexamethyl-4,4',5,5'-dibenzo-2,2'-indotricarbocyanine iodide, Styril $9=2$-(6-( p-dimethylaminophenyl)-2,4-neopentylene-1,3,5-hexatrienyl)-3-methylbenzothiazolium perchlorate, $\mathrm{ME}=$ methanol, EG = ethylene glycol, DMSO = dimethyl sulphoxide, EG:DMSO = $1: 1$ volume mixture of ethylene glycol and dimethyl sulphoxide $* \sigma_{\mathrm{L}}=\sigma_{\mathrm{em}}[27,28]$.

$\uparrow$ Assumed [66].

$\ddagger$ Assumed [33].

$\S$ Assumed [67].

I $\tau_{\mathrm{v}}^{\mathrm{L}}=4$ ps assumed [67]. 


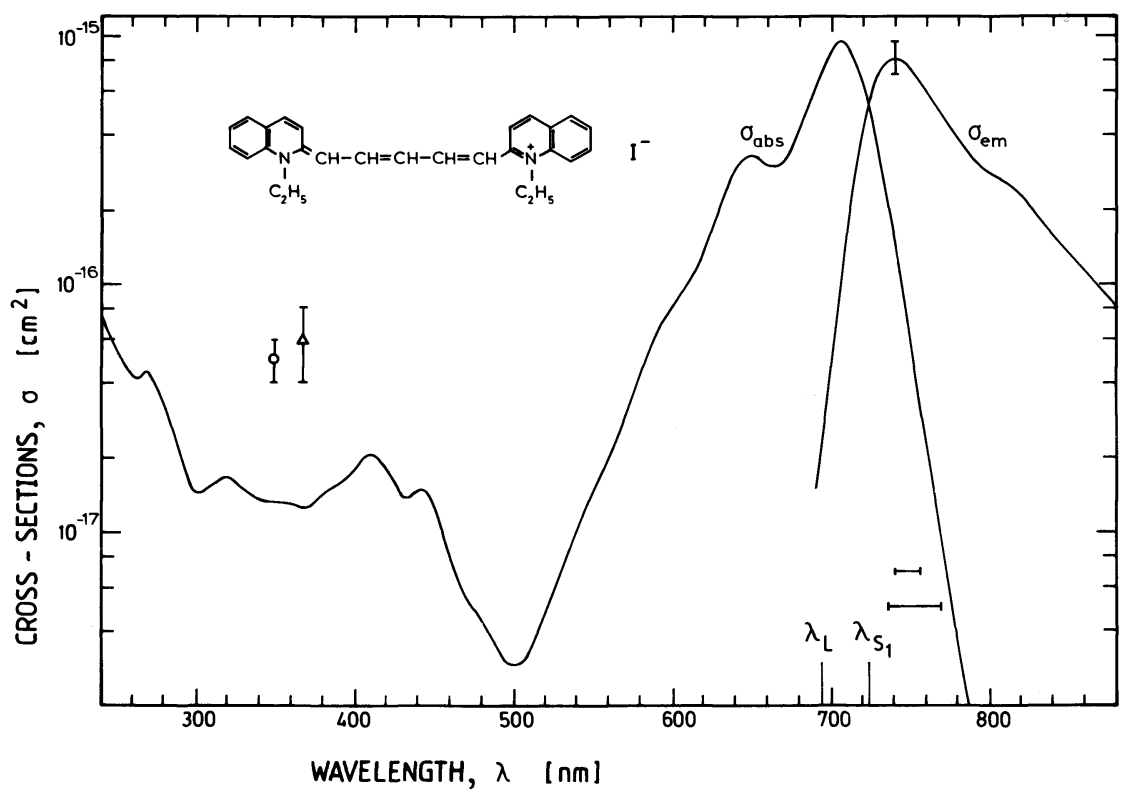

Figure 1 Absorption and emission cross-section spectra of DDI in methanol. The excited-state absorption cross-sections of pump pulse (circle) and the generated light (triangle) are included. The spectral widths of the generated light are indicated for $10^{-4} \mathrm{M} \mathrm{DDI}$ (horizontal bars for $1 / 2$ - and $1 / 10$-width). The structural formula is incuded.

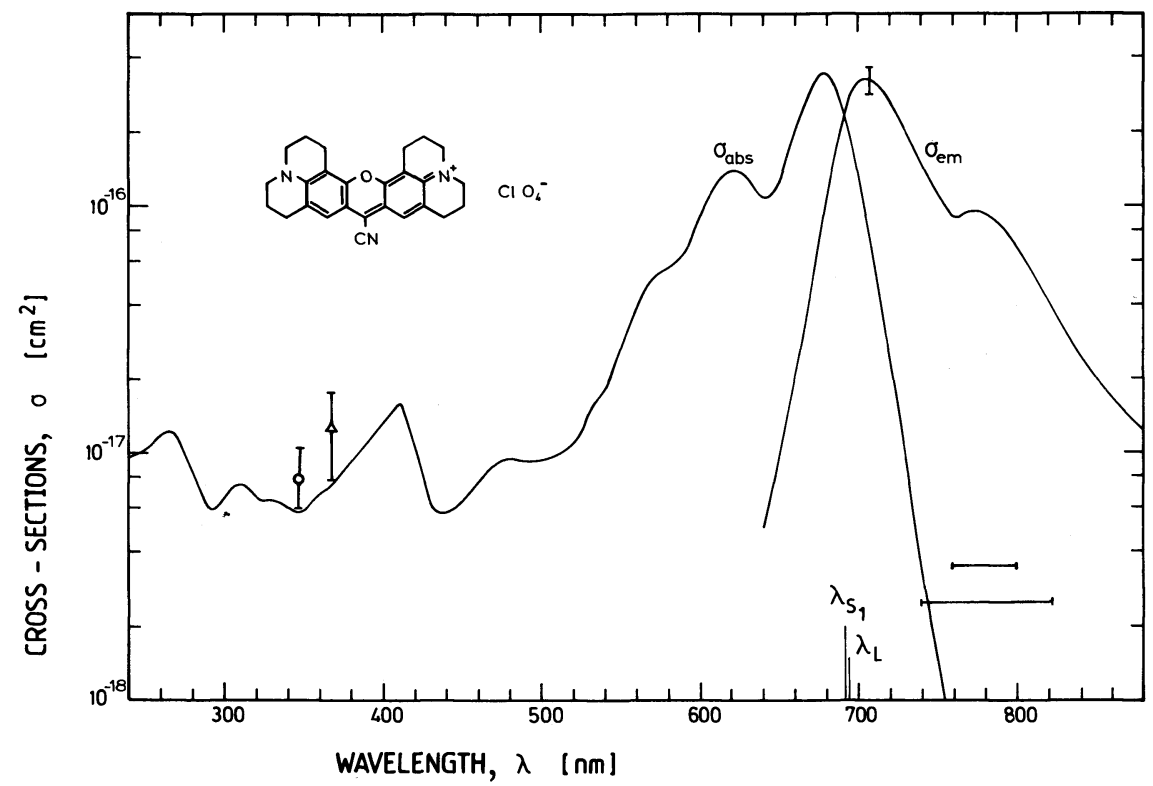

Figure 2 Absorption and emission cross-section spectra of rhodamine 800 in methanol. For explanation see Fig. 1. Horizontal bars for dye concentration of $2 \times 10^{-4} \mathrm{M}$. 


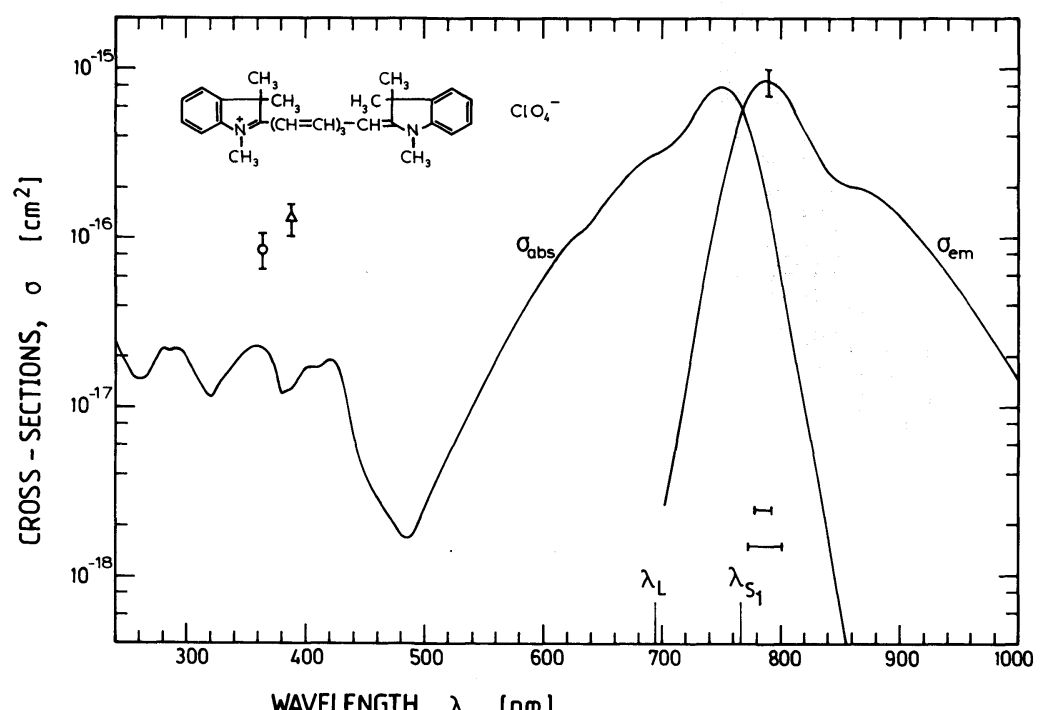

Figure 3 Absorption and emission cross-section spectra of $\mathrm{HITCl}$ in methanol. For explanation see Fig. 1. Horizontal bars for dye concentration of $7.7 \times 10^{-5} \mathrm{M}$.

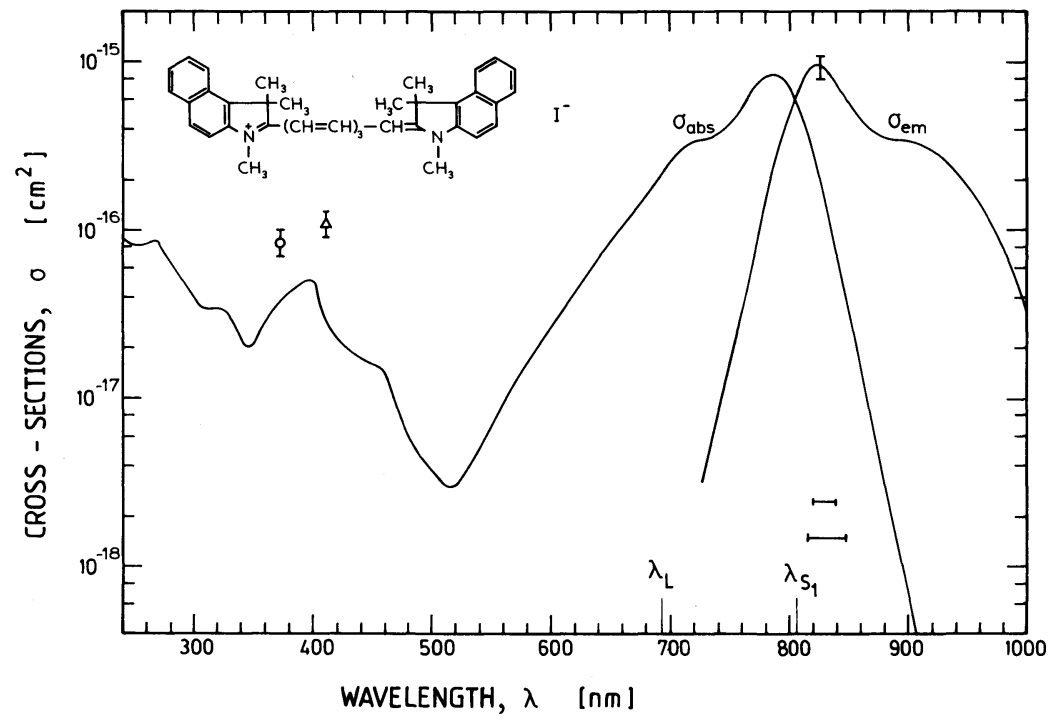

Figure 4 Absorption and emission cross-section spectra of $\mathrm{HDITCl}$ in $1: 1$ volume mixture of ethylene glycol and DMSO. For explanation see Fig. 1. Horizontal bars for dye concentration of $5.1 \times 10^{-5} \mathrm{M}$.

(see footnote to Table I for abbreviations) DDI in methanol, rhodamine 800 in methanol, HITCI in methanol, HDITCI in $1: 1$ (vol.) mixture of ethylene glycol and DMSO, styril 9 in DMSO, and IR 140 in $1: 1$ (vol.) mixture of ethylene glycol and DMSO, respectively. The structural formulae of the dyes are included in the figures.

The absorption cross-section spectra, $\sigma_{\mathrm{abs}}(\lambda)$, were measured with a spectrophotometer. Concentration-dependent absorption cross-section changes were not observed up to the 


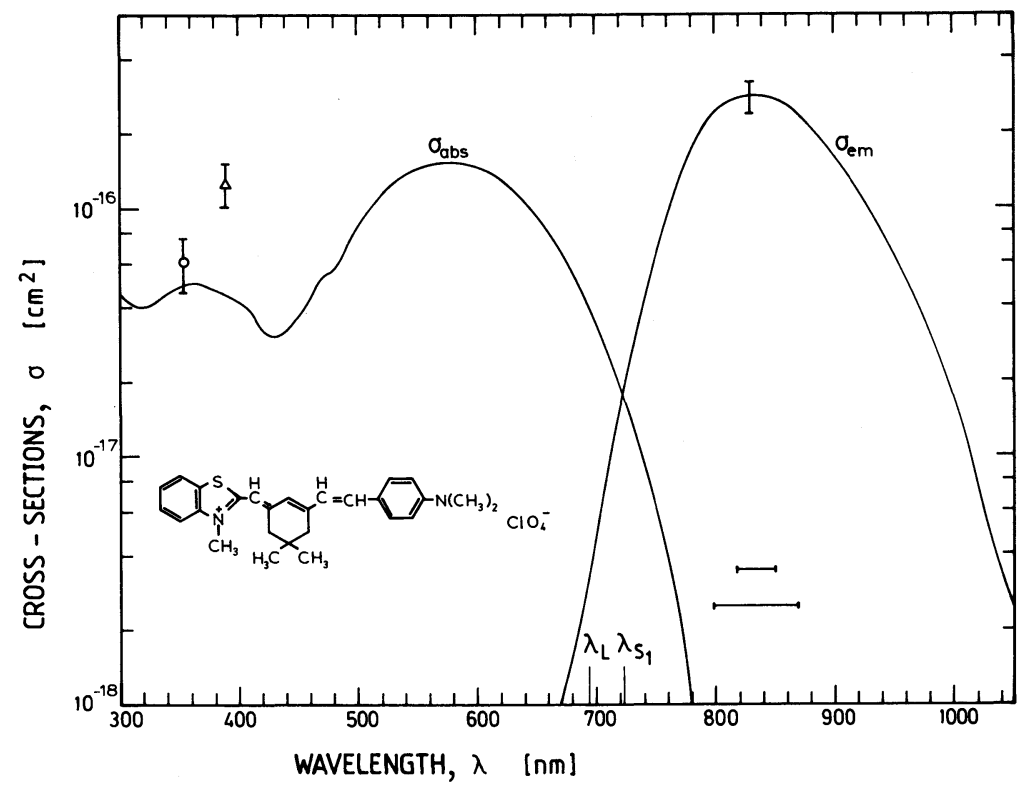

Figure 5 Absorption and emission cross-section spectra of styril 9 in DMSO. For explanation see Fig. 1. Horizontal bars for dye concentration of $2.5 \times 10^{-4} \mathrm{M}$.

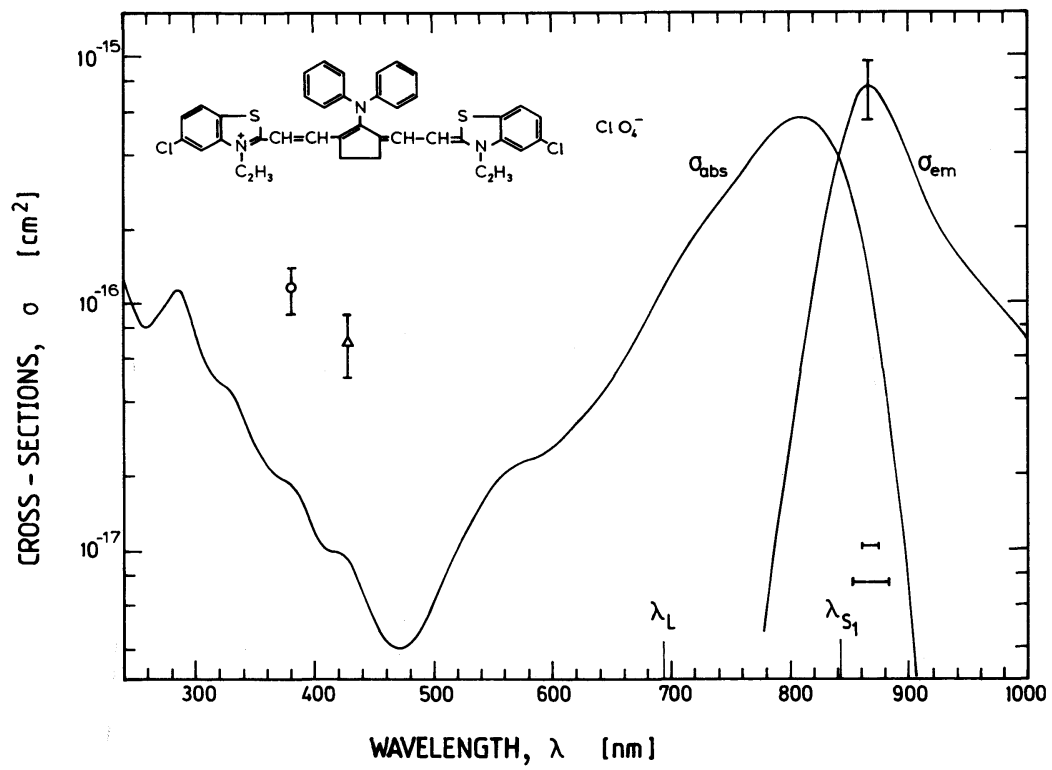

Figure 6 Absorption and emission cross-section spectra of IR 140 in $1: 1$ volume mixture of ethylene glycol and DMSO. For explanation see Fig. 1. Horizontal bars for dye concentration of $3.7 \times 10^{-5} \mathrm{M}$. 
highest applied concentrations (no remarkable dimerization contributions [21]). The stimulated emission cross-section spectra are derived from the absorption cross-section spectra and from the normalized fluorescence quantum distributions, $\widetilde{E}(\lambda)\left(\int_{\mathrm{em}} \tilde{E}(\lambda) \mathrm{d} \lambda=1\right)$, by $[22,23]$

and $[24,25]$

$$
\sigma_{\mathrm{em}}=\frac{\lambda^{4} \tilde{E}(\lambda)}{8 \pi n_{\mathrm{F}}^{2} c_{0} \tau_{\mathrm{rad}}}
$$

$$
\frac{1}{\tau_{\text {rad }}}=\frac{8 \pi n_{\mathrm{F}}^{3} c_{0}}{n_{\mathrm{A}}} \frac{\int_{\mathrm{em}} \tilde{E}(\lambda) \lambda \mathrm{d} \lambda}{\int_{\mathrm{em}} \tilde{E}(\lambda) \lambda^{4} \mathrm{~d} \lambda} \int_{\text {abs }} \frac{\sigma_{\text {abs }}(\lambda)}{\lambda} \mathrm{d} \lambda
$$

where $n_{\mathrm{F}}$ and $n_{\mathrm{A}}$ are the average refractive indices of the solutions in the $\mathrm{S}_{1}-\mathrm{S}_{0}$ emission and the $S_{0}-S_{1}$ absorption band, respectively. The integrations extend over the $S_{1}-S_{0}$ emission band $(\mathrm{em})$ and the $\mathrm{S}_{0}-\mathrm{S}_{1}$ absorption band (abs). The normalized fluorescence quantum distributions were determined using a home-made spectrofluorimeter [23]. The dotted curves in Figs 8 and 9 are proportional to $\widetilde{E}(\lambda)$ (see below, Equation 3).

The excited-state absorption cross-sections at the pump laser frequency were determined by fitting computer simulations to energy transmission measurements [26-28]. The energy transmission through DDI dissolved in methanol was reported previously [29]. The energy transmissions of the five other dyes are depicted in Fig. 7. The excited-state absorption

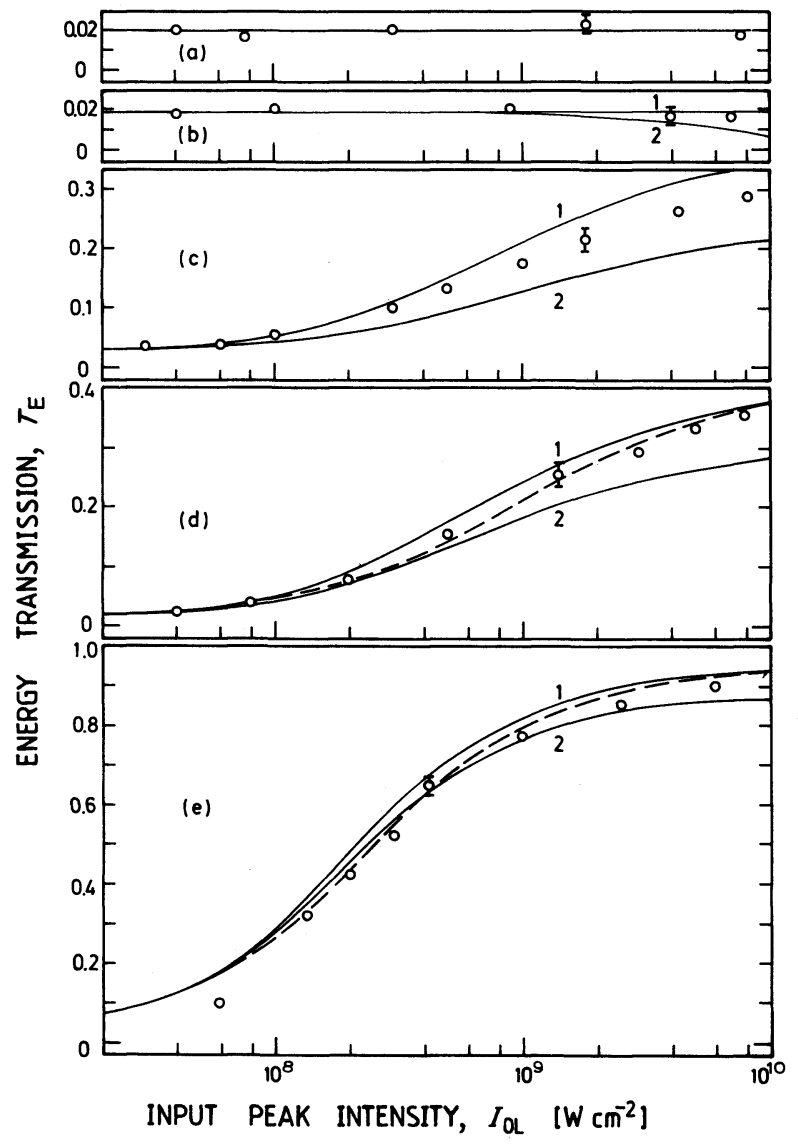

Figure 7 Non-linear transmission through dye solutions. Curves in (a) to (d) are calculated by use of level diagram of Fig. 23a $[26,33]$. Curves in (e) belong to level diagram of Fig. 23b [27, 28]. Solid curves include absorption anisotropy. (a) IR 140. Initial transmission $T_{0}=0.02$. $\sigma_{\text {ex }}^{\mathrm{L}}=\sigma_{\mathrm{L}}=$ $1.15 \times 10^{-16} \mathrm{~cm}^{2}$. (b) Styril 9. $T_{0}=0.0195$. Curve 1, $\sigma_{\mathrm{ex}}^{\mathrm{L}}=\sigma_{\mathrm{L}}=4 \times 10^{-17} \mathrm{~cm}^{2}$; curve 2, $\sigma_{\mathrm{ex}}^{\mathrm{L}}=1 \times 10^{-16} \mathrm{~cm}^{2}$. (c) HDITCl. $T_{0}=$ $0.032, \sigma_{\mathrm{L}}=2.2 \times 10^{-16} \mathrm{~cm}^{2}$. Curve 1, $\sigma_{\mathrm{ex}}^{\mathrm{L}}=$ $6.7 \times 10^{-17} \mathrm{~cm}^{2}$; curve 2, $\sigma_{\mathrm{ex}}^{\mathrm{L}}=1 \times 10^{-16} \mathrm{~cm}^{2}$. (d) HITCl. $T_{0}=0.02, \sigma_{\mathrm{L}}=3.1 \times 10^{-16} \mathrm{~cm}^{2}$. Curve 1, $\sigma_{\mathrm{ex}}^{\mathrm{L}}=7.7 \times 10^{-17} \mathrm{~cm}^{2}$; curve 2, $\sigma_{\mathrm{ex}}^{\mathrm{L}}=1 \times 10^{-16} \mathrm{~cm}^{2}$. Broken curve, $\sigma_{\text {ex }}^{L}=7.7 \times 10^{-17} \mathrm{~cm}^{2}$, without absorption anisotropy. (e) Rhodamine 800. $T_{0}=0.038$, $\sigma_{\mathrm{L}}=\sigma_{\mathrm{em}}\left(v_{\mathrm{L}}\right)=2.65 \times 10^{-16} \mathrm{~cm}^{2}, \quad \varrho_{\hat{2}}=$ $\sigma_{\text {abs }}\left(v_{\mathrm{L}}\right) / \sigma_{\text {em }}\left(v_{\mathrm{L}}\right)=0.75, \sigma_{\text {ex }}^{\mathrm{L}}=5 \times 10^{-18} \mathrm{~cm}^{2}$ (1) and $1 \times 10^{-17} \mathrm{~cm}^{2}$ (2). Broken curve, $\sigma_{\mathrm{ex}}^{\mathrm{L}}=5 \times 10^{-18} \mathrm{~cm}^{2}$, without absorption anisotropy. 
cross-sections at the ASE frequencies were determined by fitting the numerical calculations of the amplified spontaneous emission to the experimental results (Figs 11 to 16, below). The pure electronic $S_{0}-S_{1}$ transition frequency $\tilde{v}_{s_{1}}=\lambda_{S_{1}}^{-1}$ is assumed to be located at the position where $\sigma_{\text {abs }}(\lambda)=\sigma_{\text {em }}(\lambda)$.

The fluorescence lifetimes, $\tau_{\mathrm{F}}$, of the dyes investigated were determined by streak-camera measurements. Single picosecond ruby laser pulses excite the molecules. Low dye concentrations avoid an amplification of the fluorescence light. The radiative lifetime is given by Equation 2. The fluorescence quantum efficiency is related to the fluorescence lifetime and the radiative lifetime by $q_{\mathrm{F}}=\tau_{\mathrm{F}} / \tau_{\mathrm{rad}}$.

The spectral fluorescence emission efficiency, $\eta_{\mathrm{Fl}}\left(\lambda, \Delta \Theta^{\prime}\right)=\lim _{W_{\mathrm{L}} \rightarrow 0}\left[W_{\mathrm{Fl}}\left(\lambda, \Delta \Theta^{\prime}\right) / W_{\mathrm{L}}\right]$, in the forward direction within an angle of observation $\Delta \Theta^{\prime}$ (solid angle $\left.\Delta \Omega^{\prime}=\pi\left(\Delta \Theta^{\prime}\right)^{2} / 4\right)$ is given by

$$
\eta_{\mathrm{Fl}}\left(\lambda, \Delta \Theta^{\prime}\right)=\tilde{E}(\lambda) q_{\mathrm{F}} \frac{\Delta \Omega^{\prime}}{4 \pi} \beta(\lambda)=\tilde{E}(\lambda) q_{\mathrm{F}} \frac{\left(\Delta \Theta^{\prime}\right)^{2}}{16} \beta(\lambda)
$$

with

$$
\beta(\lambda)=\frac{\left.\sigma_{\mathrm{abs}}\left(\lambda_{\mathrm{L}}\right)\left\{\exp \left[-\sigma_{\mathrm{abs}}(\lambda) N_{0} l\right]-\exp \left[-\sigma_{\mathrm{abs}}\left(\lambda_{\mathrm{L}}\right) N_{0} l\right)\right]\right\}}{\left[\sigma_{\mathrm{abs}}\left(\lambda_{\mathrm{L}}\right)-\sigma_{\mathrm{abs}}(\lambda)\right]\left\{1-\exp \left[-\sigma_{\mathrm{abs}}\left(\lambda_{\mathrm{L}}\right) N_{0} l\right]\right\}}
$$

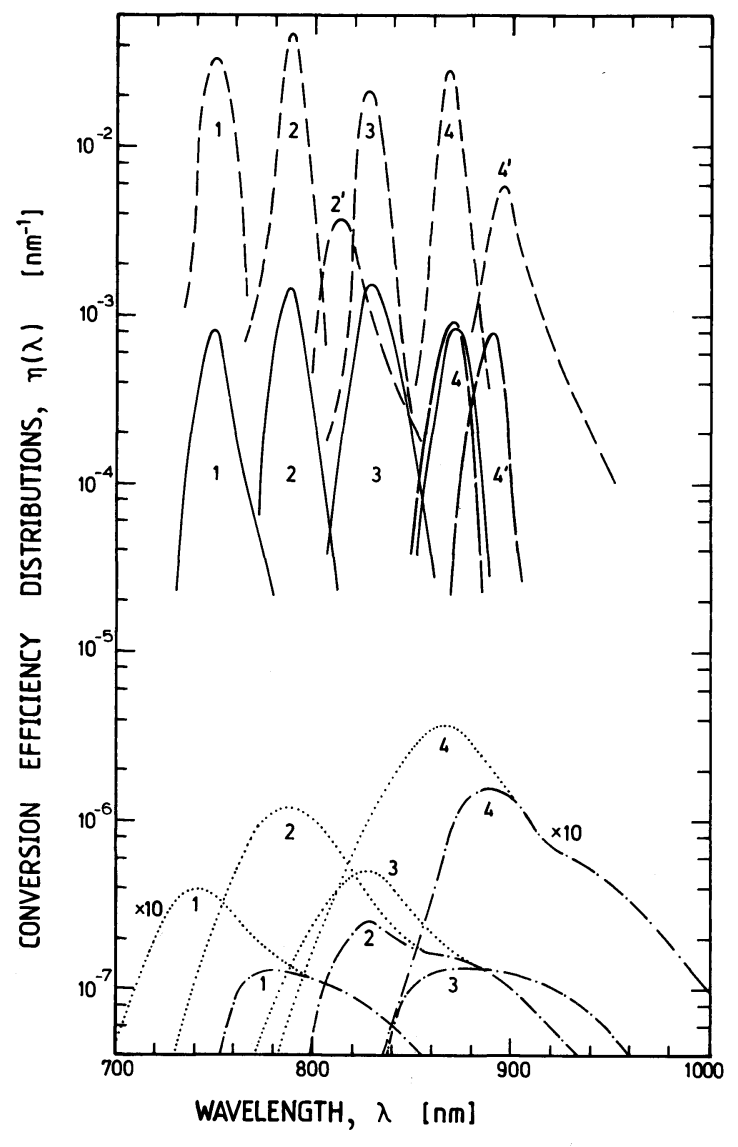

Figure 8 Spectral distribution of generated light in dye solutions. Dye parameters are given in Table I. Chain-broken curves, spontaneous emission $\eta_{F 1}(\lambda)$ in the forward direction within divergence angle of $\Delta \Theta^{\prime}=6^{\circ}$ (Equation 3). Dotted curves, $\eta_{\mathrm{F} 1}(\lambda) / \beta(\lambda)$. Curves are proportional to the fluorescence quantum distribution $E(\lambda)$. Full curves, amplified spontaneous emission $\eta_{\text {ASE }}(\lambda)$ after generator cell at pump pulse peak intensity of $I_{\mathrm{OL}} \approx 4 \times 10^{9} \mathrm{~W} \mathrm{~cm}^{-2}$. Broken curves, spectral distribution of amplified signal after amplifier A2, $\eta_{\text {AMP }}(\lambda)$. Input peak intensity to generator cell is $I_{\mathrm{oL}} \approx 4 \times 10^{9} \mathrm{~W} \mathrm{~cm}^{-2}$ (Fig. 10). Curves (1) $10^{-4} \mathrm{M}$ DDI, (2) $7.7 \times 10^{-5} \mathrm{M} \mathrm{HITCl},\left(2^{\prime}\right) 5.6 \times 10^{-4} \mathrm{M} \mathrm{HITCl}$, (3) $5.1 \times 10^{-5} \mathrm{M} \mathrm{HDITCl}$, (4) $3.7 \times 10^{-5} \mathrm{M}$ IR 140, (4') $5 \times 10^{-4} \mathrm{M}$ IR 140. Long-broken curves are calculated $\eta_{\text {ASE }}(\lambda)$ distributions for $3.7 \times 10^{-5} \mathrm{M}$ IR $140 \quad(4)$ and $5 \times 10^{-4} \mathrm{M}$ IR $140\left(4^{\prime}\right)$. 


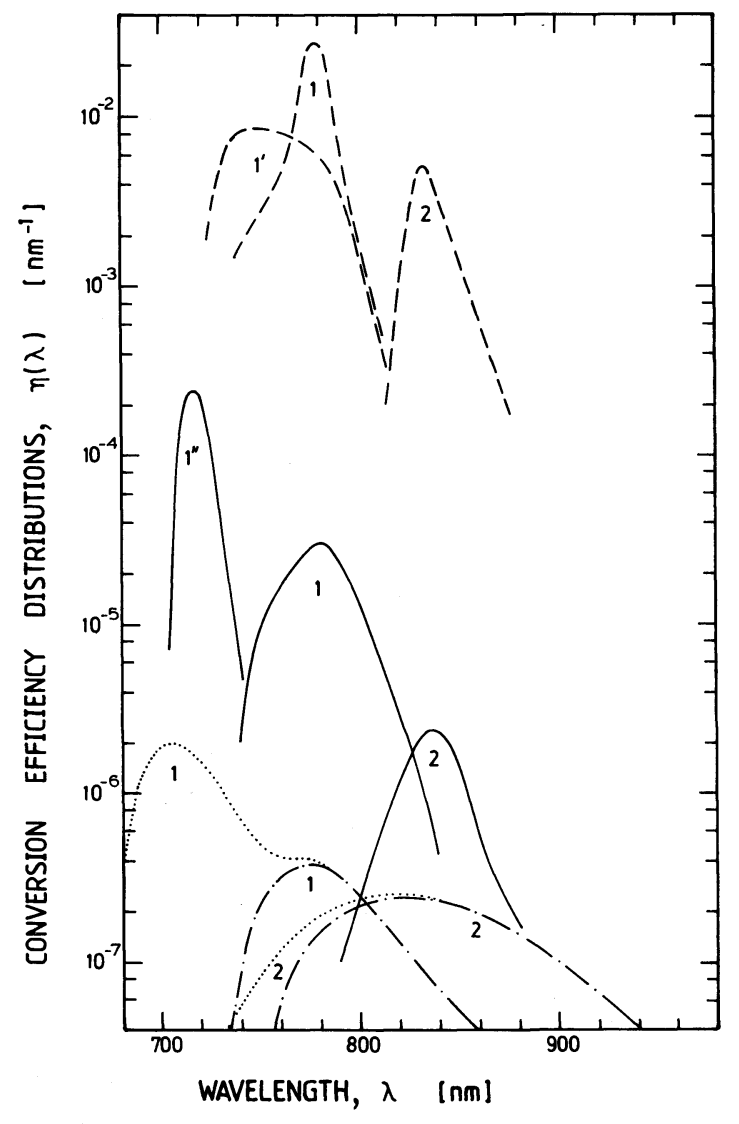

Figure 9 Spectral distribution of generated light in dye solutions. For legend see Fig. 8. Curves (1) $2 \times 10^{-3} \mathrm{M}$ rhodamine $800,\left(1^{\prime}\right) 10^{-3} \mathrm{M}$ rhodamine $800,\left(1^{\prime \prime}\right) 5 \times 10^{-4} \mathrm{M}$ rhodamine 800 , (2) $2.5 \times 10^{-4} \mathrm{M}$ styril 9 .

$\beta(\lambda)=\int_{0}^{l}\left(\partial W_{\mathrm{L}} / \partial z\right) \exp \left[-\sigma_{\mathrm{abs}}(\lambda) N_{0}(l-z)\right] \mathrm{d} z / \int_{0}^{l}\left(\partial W_{\mathrm{L}} / \partial z\right) \mathrm{d} z=\int_{0}^{l} \exp \left[-\sigma_{\mathrm{abs}}\left(\lambda_{\mathrm{L}}\right) N_{0} z\right] \times$ $\exp \left[\sigma_{\text {abs }}(\lambda) N_{0}(l-z)\right] \mathrm{d} z / \int_{0}^{l} \exp \left[-\sigma_{\text {abs }}\left(\lambda_{\mathrm{L}}\right) N_{0} z\right] \mathrm{d} z$ takes care of the pump pulse absorption and of the reabsorption of fluorescence light along the sample; $\sigma_{\mathrm{abs}}\left(\lambda_{\mathrm{L}}\right)$ is the absorption cross-section of the pump laser; $N_{0}$ is the number density of dye molecules; $l$ is the sample length; and the limit $W_{\mathrm{L}} \rightarrow 0$ excludes bleaching effects. The $\eta_{\mathrm{FI}}\left(\lambda, 6^{\circ}\right)$-curves of the dye solutions investigated are included in Figs 8 and 9 (chain-broken curves). $\eta_{\mathrm{Fl}}(\lambda) / \beta(\lambda)$ is illustrated by the dotted curves.

\section{Experimental}

The experimental set-up is depicted in Fig. 10. The passively mode-locked ruby laser generates a train of picosecond pulses (saturable absorber DDI in methanol, single-pass transmission is 0.80 ). The pulse durations are somewhat shortened by the saturable cell SA behind the laser oscillator [30] (dye DDI, small signal transmission 0.1). A single pulse was selected with a Pockels cell shutter. The duration of the selected pulse was approximately $30 \mathrm{ps}$. The pulse energy was increased up to a factor of 100 by a double passage through the ruby amplifier. In the seeding pulse amplification experiments a picosecond continuum was generated in the ruby crystal by focusing the laser pulses into the amplifier (lens L1, focal length $f_{1}=2.5 \mathrm{~m}$ ). For the amplified spontaneous emission experiment lens L1 was replaced by a beam-narrowing telescope. 


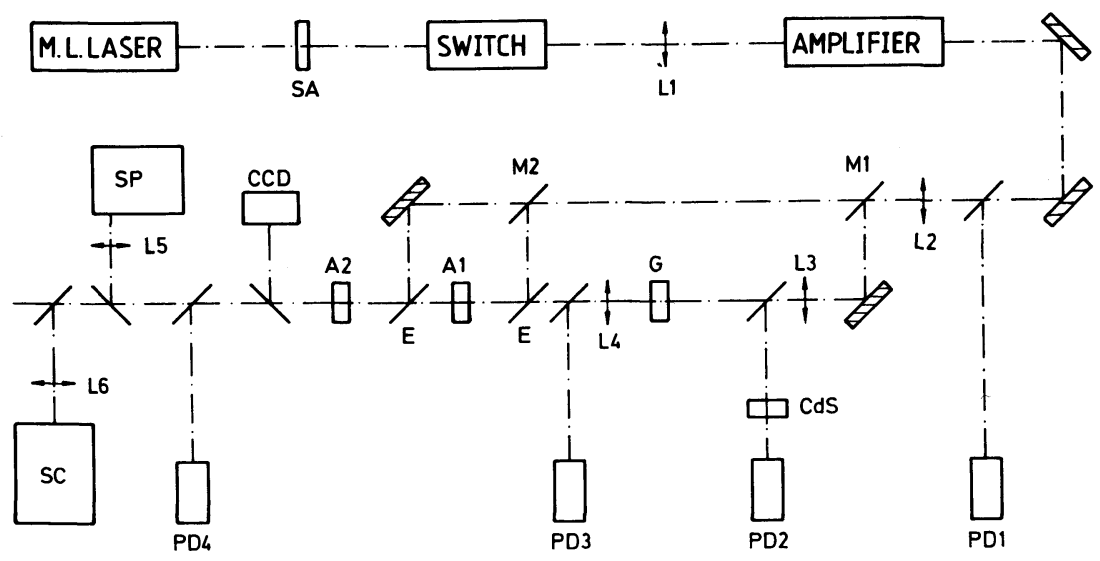

Figure 10 Experimental set-up. SA, saturable absorber; L1 to L6, lenses; M1, M2, partial reflecting mirrors; G, dye generator cell; A1, A2, dye amplifier cells; E, long-pass mirror; CdS, CdS crystal for intensity detection [31]; PD1 to PD4, photodetectors; CCD, two-dimensional CCD camera; SP, spectrometer; SC, streak camera.

The experimental set-up was used to study (a) the amplification of spontaneous emission in the generator cell $\mathrm{G}$ (ASE), (b) the amplification of radiation in the dye amplifiers A1 and A2 (AMP), and (c) the amplification of the seeding picosecond continuum in the cell $G$ (SPA) and in the amplifiers A1 and A2.

For the investigation of the amplified spontaneous emission (ASE) a $100 \%$ reflecting mirror M1 was mounted, and the lenses L3, L4 and the dye cells A1, A2 were removed.

For the amplification studies (AMP) the complete generator-amplifier system of Fig. 1 was operated (L1 out and L3 in for ASE amplification; L1 in and L3 out for SPA). Mirror reflectivities of $R_{1}=30 \%(\mathrm{M} 1)$ and $R_{2}=50 \%(\mathrm{M} 2)$ were used. In part of the amplification experiments the radiation behind the generator cell was collimated with lens $\mathrm{L} 4\left(f_{4}=5 \mathrm{~cm}\right)$. The long-pass edge-mirrors $E$ reflected the ruby light and transmitted the dye emission.

The SPA in the generator cell was studied with the same arrangement as the ASE. Only lens L1 was inserted and lens L3 was removed. The further amplification in the dye cells A1 and A2 was carried out without lens L4.

The peak intensity of the pump pulses incident to the generator cell was determined by two-photon transmission measurement through a CdS crystal (photodetectors PD1 and PD2) [31]. The energies of the generated light pulses were monitored with detectors PD3 and PD4. The beam profile and the radiation divergence were measured with a twodimensional CCD camera. The spectra were registered with the grating spectrometer SP. The temporal pulse profiles were detected with the streak camera SC. Time-resolved spectra were recorded with the streak camera behind the spectrometer.

The spectral narrowing and tuning of the generated radiation by a grating spectrometer and the re-amplification of the selected spectrum was described recently [10] and is not repeated here.

\section{Results}

\subsection{Amplified spontaneous emission}

The energy conversion efficiency $\eta_{\mathrm{ASE}}=W_{\mathrm{ASE}} / W_{\mathrm{L}}$, versus pump pulse peak intensity $I_{0 \mathrm{~L}}$ is depicted in Figs 11 to 16 for the various dyes (circles). $W_{\mathrm{ASE}}$ is the emitted energy in the forward direction within an observation angle of $\Delta \Theta^{\prime}=6^{\circ} . W_{\mathrm{L}}$ is the energy of the pump 


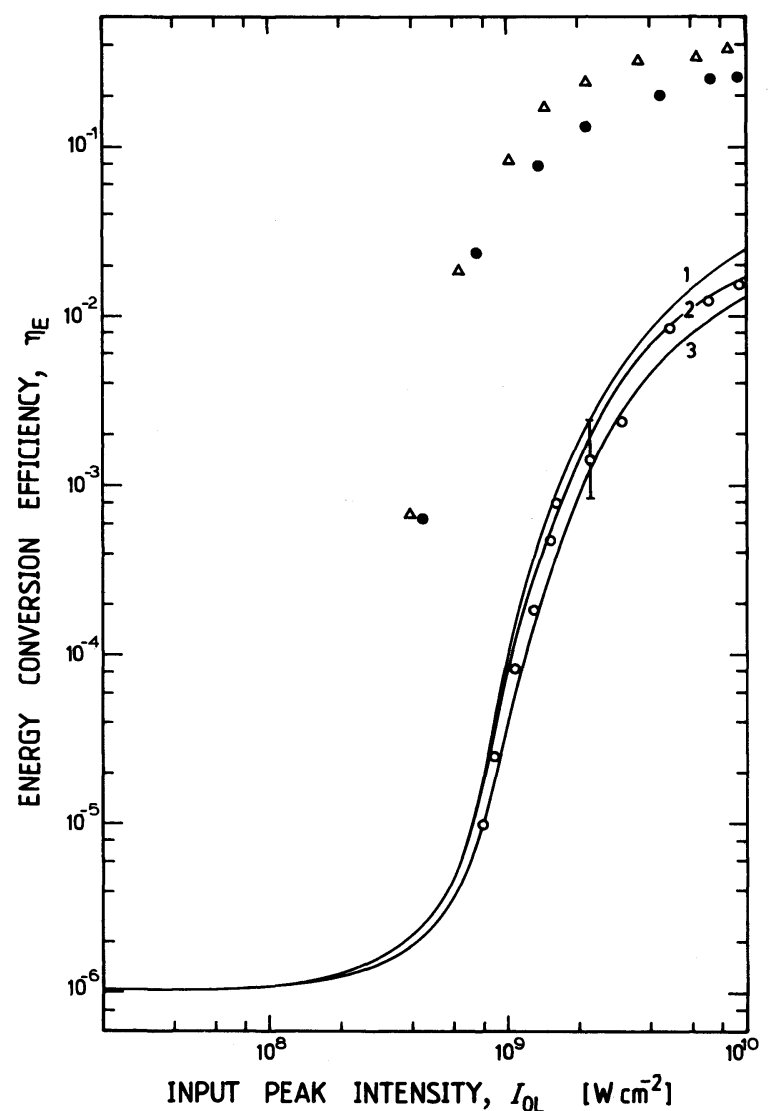

Figure 11 Energy conversion efficiencies in DDI $\left(10^{-4} \mathrm{M}\right)$ generator and amplifier system. Circles, $\eta_{\text {ASE }}=W_{\text {ASE }} / W_{L}$ behind generator cell. $W_{\mathrm{L}}$ is input pump pulse energy in front of the generator cell. Filled circles and triangles, $\eta_{\text {AMP }}=W_{\text {AMP }} / W_{L} \cdot W_{\text {AMP }}$ is measured after amplifier A2. Filled circles, uncollimated ASE signal (without lens $L 4$ of Fig. 10); triangles, collimated ASE signal. Curves are calculated for amplified spontaneous emission in generator cell with data of Table $I$ and (1) $\sigma_{\mathrm{ex}}^{\mathrm{ASE}}=0$, (2) $\sigma_{\mathrm{ex}}^{\mathrm{ASE}}=$ $5 \times 10^{-17} \mathrm{~cm}^{2}$, (e) $\sigma_{\mathrm{ex}}^{\mathrm{ASE}}=1 \times 10^{-16} \mathrm{~cm}^{2}$.

pulse before the generator cell. At low pump pulse intensities the spontaneous emission $\eta_{\mathrm{F} 1}$ is measured $\left(\eta_{\mathrm{Fl}}=\int_{\mathrm{em}} \eta_{\mathrm{Fl}}(\lambda) \mathrm{d} \lambda\right.$, see Equation 3). At high intensities the ASE signal saturates. The slight decrease of the signals of Figs 13 to 16 is due to excited-state absorption of the ASE signal and of the pump pulse (see below). Amplified spontaneous emission in the backward direction is expected for dyes with fluorescence lifetimes $\tau_{\mathrm{F}}>n_{\mathrm{F}} l_{\mathrm{eff}} / c_{0}\left(n_{\mathrm{F}}\right.$ is the refractive index in the wavelength region of the ASE signal, and $l_{\text {eff }}$ the penetration depth of the pump pulse). In the case of $10^{-4} \mathrm{M}$ DDI in methanol $\left(\tau_{\mathrm{F}} \approx 17 \mathrm{ps}\right)$ the amplification of spontaneous emission in the backward direction is very weak $\left(\eta_{\mathrm{E}}\right.$ (backward)/ $\eta_{\mathrm{E}}($ forward $) \approx 10^{-3}$ at $I_{0 \mathrm{~L}} \approx 5 \times 10^{9} \mathrm{~W} \mathrm{~cm}^{-2}$ ). For $7.7 \times 10^{-5} \mathrm{M} \mathrm{HITCI}$ in methanol $\left(\tau_{\mathrm{F}} \approx 120 \mathrm{ps}\right)$ the ratio of backward to forward ASE signal was found to be approximately 0.05 at $I_{0 \mathrm{~L}} \approx 5 \times 10^{9} \mathrm{~W} \mathrm{~cm}^{-2}$.

The spectral efficiency distributions, $\eta_{\mathrm{ASE}}(\lambda)=\left(\partial W_{\mathrm{ASE}} / \partial \lambda\right) / W_{\mathrm{L}}$, of the generated ASE signals are depicted by the solid curves in Figs 8 and $9\left(\int_{\mathrm{em}} \eta_{\mathrm{ASE}}(\lambda) \mathrm{d} \lambda=\eta_{\mathrm{ASE}}\right)$. The curves belong to an input peak intensity of $I_{0 \mathrm{~L}} \approx 4 \times 10^{9} \mathrm{~W} \mathrm{~cm}^{-2}$. The spectra are narrowed compared with the spontaneous emission spectra $\eta_{\mathrm{Fl}}(\lambda)$ (chain-broken curves in Figs 8 and 9).

The spectral widths, $\Delta \lambda_{\mathrm{ASE}}$, and the wavelengths of peak emission, $\lambda_{\mathrm{ASE}, \max }$, vary with pump pulse intensity and dye concentration. In Fig. $17 \Delta \lambda_{\mathrm{ASE}}$ and $\lambda_{\mathrm{ASE} \text {, max }}$ versus $I_{0 \mathrm{~L}}$ are depicted for the $10^{-4} \mathrm{M}$ dye DDI. The other dyes behave similarly. Their $\Delta \lambda_{\mathrm{ASE}}$ and $\lambda_{\mathrm{ASE}, \max }$ 


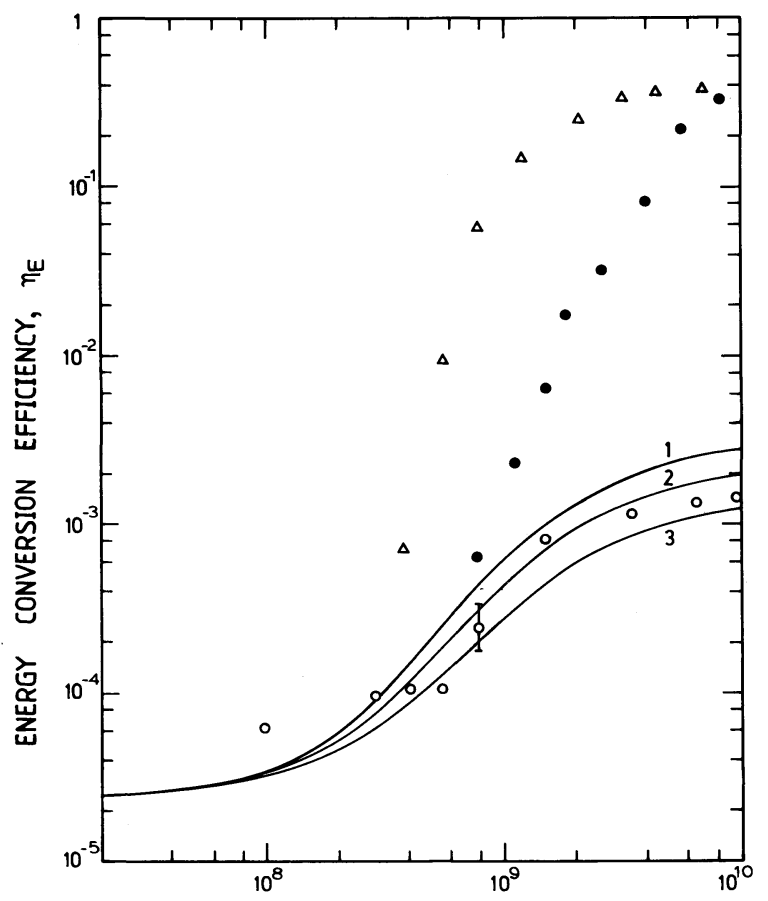

INPUT PEAK INTENSITY, $I_{0 \mathrm{~L}}\left[\mathrm{~W} \mathrm{~cm}^{-2}\right]$

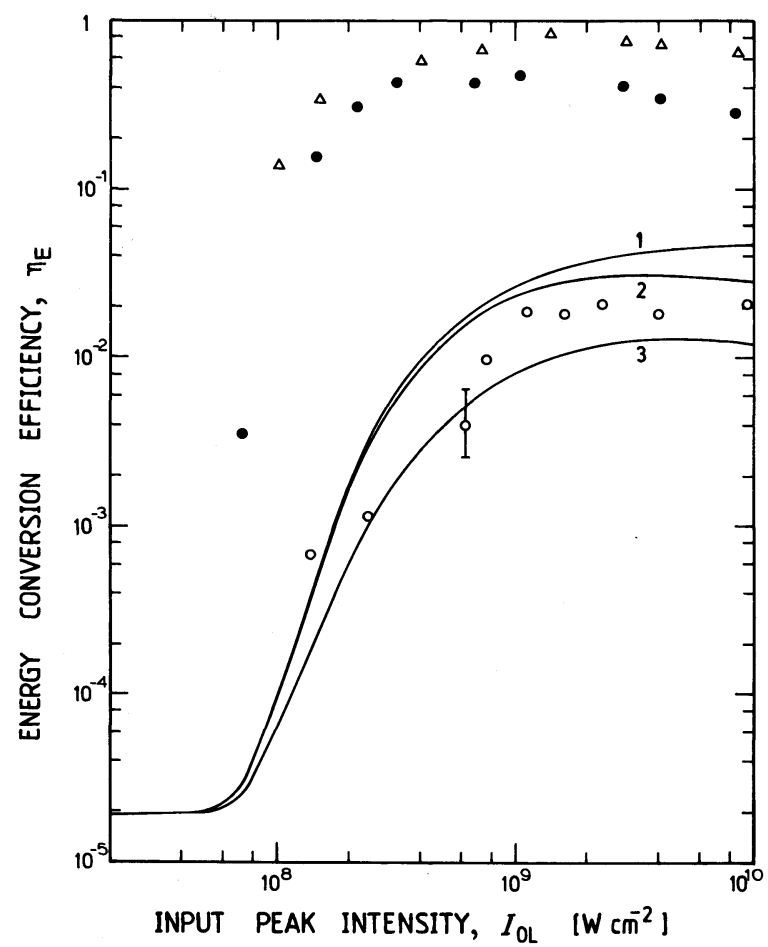

Figure 12 Energy conversion efficiencies in rhodamine $800\left(2 \times 10^{-3} \mathrm{M}\right)$ generator and amplifier system. For legend see Fig. 11. Curve $1, \sigma_{\mathrm{ex}}^{\mathrm{ASE}}=0$; curve $2, \sigma_{\mathrm{ex}}^{\mathrm{ASE}}=1 \times$ $10^{17} \mathrm{~cm}^{2}$; curve $3, \sigma_{\mathrm{ex}}^{\mathrm{ASE}}=2 \times 10^{-17} \mathrm{~cm}^{2}$.

Figure 13 Energy conversion efficiencies in $\mathrm{HITCl}\left(7.7 \times 10^{-5} \mathrm{M}\right)$ generator and amplifier system. For legend see Fig. 11. Curve 1 , $\sigma_{\mathrm{ex}}^{\mathrm{ASE}}=0$; curve 2, $\sigma_{\mathrm{ex}}^{\mathrm{ASE}}=1 \times 10^{-16} \mathrm{~cm}^{2}$; curve 3, $\sigma_{\mathrm{ex}}^{\mathrm{ASE}}=2 \times 10^{-16} \mathrm{~cm}^{2}$. 

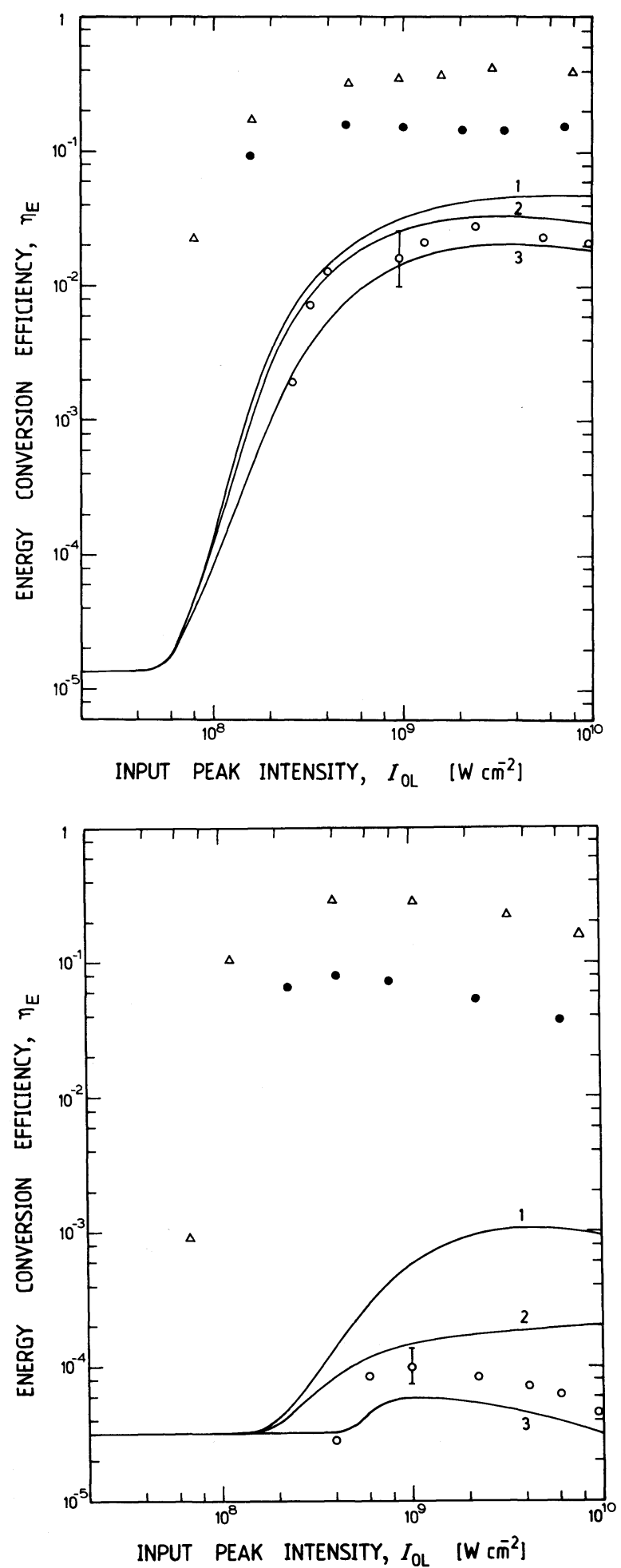

Figure 14 Energy conversion efficiencies in $\mathrm{HDITCl}\left(5.1 \times 10^{-5} \mathrm{M}\right)$ generator and amplifier system. For legend see Fig. 11. Curve 1, $\sigma_{\mathrm{ex}}^{\mathrm{ASE}}=0$; curve 2, $\sigma_{\mathrm{ex}}^{\mathrm{ASE}}=8.5 \times$ $10^{-17} \mathrm{~cm}^{2}$; curve $3, \sigma_{\mathrm{ex}}^{\mathrm{ASE}}=1.5 \times 10^{-16} \mathrm{~cm}^{2}$.

Figure 15 Energy conversion efficiencies in styril $9\left(2.5 \times 10^{-4} \mathrm{M}\right)$ generator and amplifier system. For legend see Fig. 11. Curve 1, $\sigma_{\mathrm{ex}}^{\mathrm{ASE}}=0$; curve 2, $\sigma_{\mathrm{ex}}^{\mathrm{ASE}}=10^{-16} \mathrm{~cm}^{2} ;$ curve 3, $\sigma_{\text {ex }}^{\text {ASE }}=1.5 \times 10^{-16} \mathrm{~cm}^{2}$. 

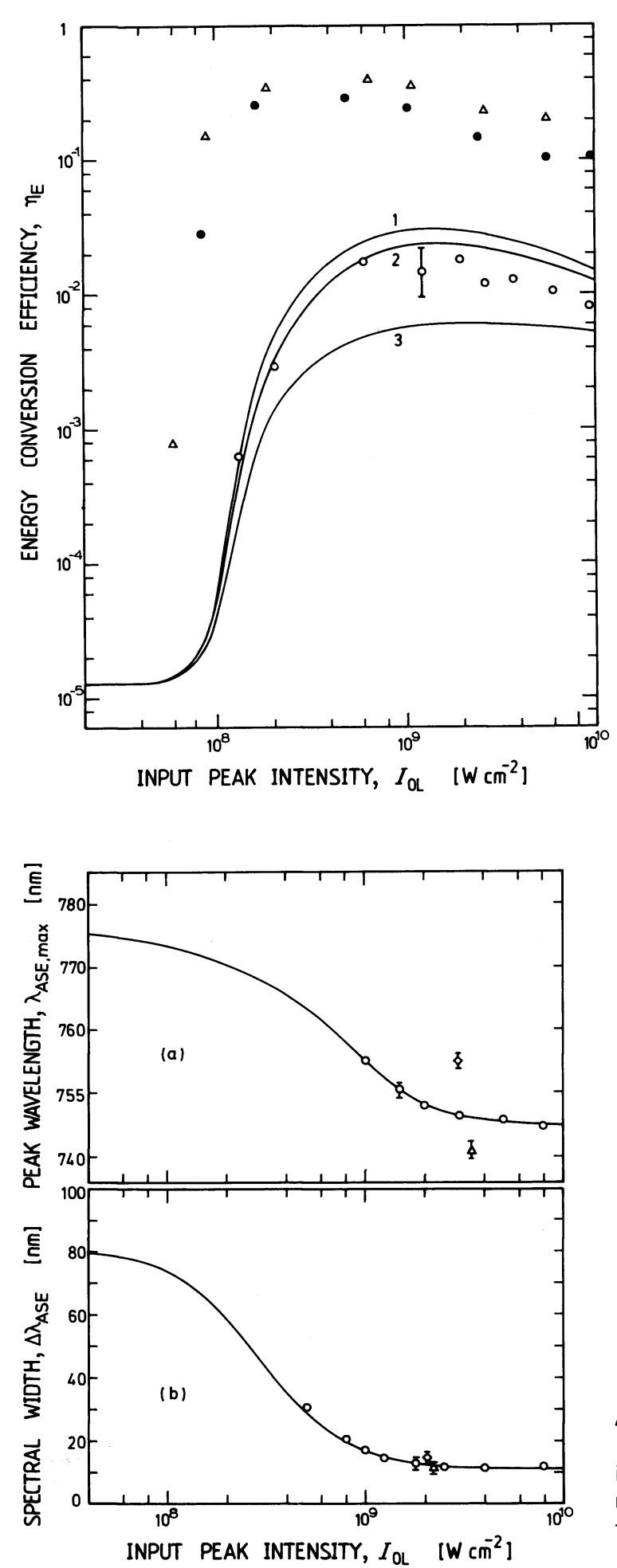

Figure 16 Energy conversion efficiencies in IR $140\left(3.7 \times 10^{-5} \mathrm{M}\right)$ generator and amplifier system. For legend see Fig. 11. Curve 1 , $\sigma_{\mathrm{ex}}^{\mathrm{ASE}}=0$; curve 2, $\sigma_{\mathrm{ex}}^{\mathrm{ASE}}=5 \times 10^{-17} \mathrm{~cm}^{2}$; curve 3, $\sigma_{\mathrm{ex}}^{\mathrm{ASE}}=1 \times 10^{-16} \mathrm{~cm}^{2}$.

Figure 17 Spectral shift (a) and spectral width (b) of ASE radiation behind generator cell versus input pump pulse peak intensity. Dye is DDI in methanol. Circles, concentration $C=10^{-4} \mathrm{M}$; triangle, $C=8 \times 10^{-5} \mathrm{M}$; diamond, $C=2 \times$ $10^{-4} \mathrm{M}$. 


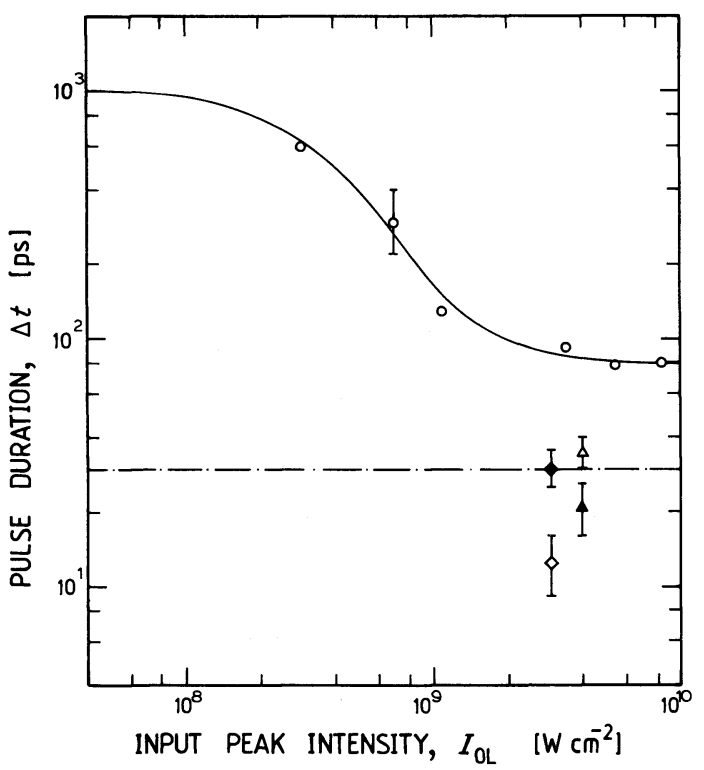

Figure 18 Pulse duration (FWHM) of generated radiation versus input pump pulse peak intensity to generator cell. Dye is $2 \times 10^{-3} \mathrm{M}$ rhodamine 800 in methanol. Circles, ASE signal after generator cell. Full curve represents leastsquares fit. Triangles depict ASE signal after amplifer A2. Open triangle, ASE signal is not collimated. Filled triangle, ASE signal is collimated behind generator cell. Open diamond, seeding pulse after generator cell. Filled diamond, seeding pulse after amplifier A2. Chainbroken line indicates pump pulse duration.

values at $I_{0 \mathrm{~L}} \approx 4 \times 10^{9} \mathrm{~W} \mathrm{~cm}^{-2}$ are given in Table $\mathrm{I}$. The spectral distribution of the stimulated emission cross-sections (Figs 1 to 6 ) is responsible for the spectral narrowing. The short-wavelength shift at high pump intensities is due to bleaching of the reabsorption. Without reabsorption the emission would centre at the wavelength of maximum stimulated emission cross-section.

The decrease of the ASE pulse duration with pump pulse intensity is illustrated in Fig. 18 for the $2 \times 10^{-3} \mathrm{M}$ rhodamine 800 solution (circles and solid curve). For $I_{0 \mathrm{~L}}<$ $10^{8} \mathrm{~W} \mathrm{~cm}^{-2}$ the pulse duration $\Delta t_{\mathrm{ASE}}(\mathrm{FWHM})$ is given by the fluorescence lifetime, i.e. $\Delta t_{\mathrm{ASE}} \approx \ln (2) \tau_{\mathrm{F}} \approx 1 \mathrm{~ns}$. For $I_{0 \mathrm{~L}} \gtrsim 5 \times 10^{9} \mathrm{~W} \mathrm{~cm}^{-2}$ the duration is $\Delta t_{\mathrm{ASE}} \approx 80 \mathrm{ps}$. The ASE pulse durations at $I_{0 \mathrm{~L}} \approx 4 \times 10^{9} \mathrm{~W} \mathrm{~cm}^{-2}$ are collected in Table I for the various dye solutions.

The beam divergence, $\Delta \Theta_{\mathrm{ASE}}$ (FWHM), of the ASE signal narrows with pump intensity. Fig. 19 depicts $\Delta \Theta_{\mathrm{ASE}}$ versus $I_{0 \mathrm{~L}}$ for the $10^{-4} \mathrm{M}$ DDI solution (circles). The divergence angles of all dyes investigated are listed in Table I for $I_{0 \mathrm{~L}} \approx 4 \times 10^{9} \mathrm{~W} \mathrm{~cm}^{-2}$. The divergence angle is given approximately by

$$
\Delta \Theta_{\mathrm{ASE}} \approx \frac{d}{l_{\mathrm{eff}}} \kappa\left(G_{0}\right)
$$

where $d$ is the beam diameter (FWHM) of the pump pulse; $l_{\text {eff }}$ is the effective interaction length of the pump pulse in the generator cell - that is, the minimum of the sample length and the penetration depth (at the penetration depth the pump pulse is reduced to $e^{-1}$ of the input intensity value); and $\kappa\left(G_{0}\right)$ is a gain-dependent narrowing factor. This factor may be estimated from the relation $G\left(r^{\prime}\right)=\exp \left[\sigma_{\mathrm{em}}^{\mathrm{ASE}} N_{3}\left(r^{\prime}\right) l_{\mathrm{eff}}\right]=\exp \left\{\sigma_{\mathrm{em}}^{\mathrm{ASE}} N_{30} \exp \left[-\left(r^{\prime} / r_{0}\right)^{2}\right] l_{\mathrm{eff}}\right\}=$ $\mathrm{G}_{0} \exp \left[-\left(r^{\prime} / r_{0}\right)^{2}\right]=G_{0} / 2$ and $\kappa\left(G_{0}\right)=r^{\prime} / r_{0} . N_{3}(r)=N_{30} \exp \left[-\left(r / r_{0}\right)^{2}\right]$ is the number density of the $S_{1}$-level population of the dyes, $r^{\prime}$ is the half-width of the beam radius of the generated ASE signal at $l_{\mathrm{eff}}$. The relation gives

$$
\kappa\left(G_{0}\right)=\left[\ln \left(\frac{\ln \left(G_{0}\right)}{\ln \left(G_{0}\right)-\ln (2)}\right)\right]^{1 / 2}
$$




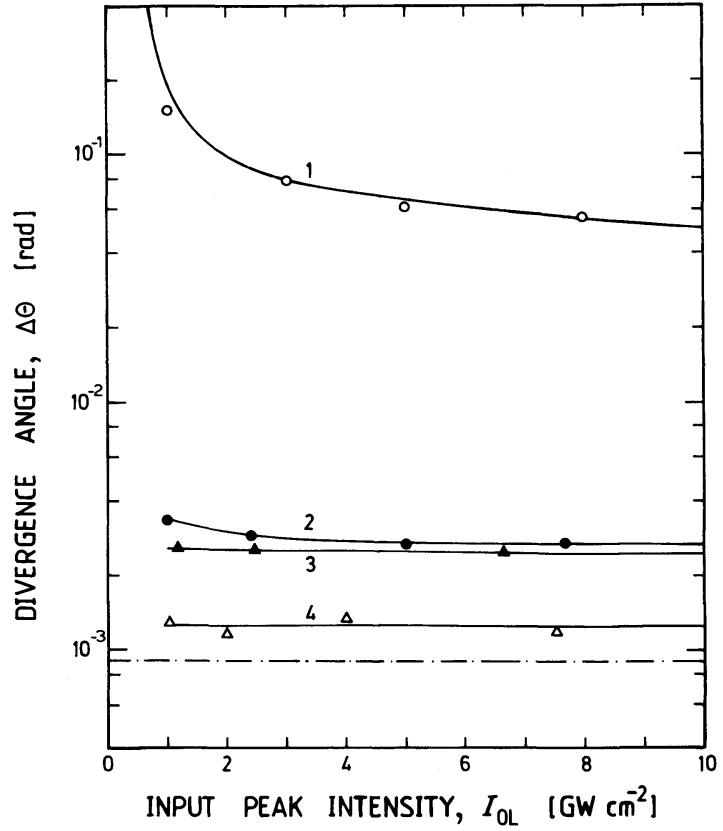

Figure 19 Divergence angle (FWHM) of generated radiation in $10^{-4} \mathrm{M}$ DDI generator amplifier system. Circles and curve 1, ASE signal behind generator cell. Filled circles and curve 2 , ASE signal after amplifier A2. Filled triangles and curve 3 , seeding pulse after amplifier A2. Open triangles and curve 4, seeding pulse after generator cell. Curve 1 is calculated (Equations 4 to 6), other curves are leastsquares fits. Chain-broken line indicates pump pulse divergence.

The peak gain factor $G_{0}=\exp \left(\sigma_{\mathrm{em}}^{\mathrm{ASE}} N_{30} l_{\mathrm{eff}}\right)$ is given approximately by

$$
G_{0} \approx \frac{\eta_{\mathrm{ASE}} \Delta t_{\mathrm{Fl}}}{\Delta t_{\mathrm{ASE}} \eta_{\mathrm{Fl}}}=\frac{\eta_{\mathrm{ASE}} \ln (2) \tau_{\mathrm{F}}}{\eta_{\mathrm{Fl}} \Delta t_{\mathrm{ASE}}}
$$

In Fig. 20 two ASE spectra of DDI $\left(10^{-4} \mathrm{M}\right)$ are presented $\left(I_{0 \mathrm{~L}} \approx 4 \times 10^{9} \mathrm{~W} \mathrm{~cm}^{-2}\right)$. The smooth curve (b) is obtained by collecting all ASE light within the acceptance angle $\Delta \Theta^{\prime}=6^{\circ}$. The structured curve (a) contains only ASE light within an aperture angle of $0.08^{\circ}$. The interference effects of the radiation are clearly seen. The spectral width of the spikes is approximately $\Delta \tilde{v}_{\text {spike }} \approx 6 \mathrm{~cm}^{-1}$, corresponding to a fluctuation duration of approximately 5 ps. The coherence length of the ASE signal was measured with a Michelson interferometer. The measured coherence length of $l_{\text {coh }} \approx 50 \mu \mathrm{m}$ corresponds to a coherence duration of $\Delta t_{\text {coh }} \approx 0.17 \mathrm{ps}$ and a spectral width of $\Delta \tilde{v}_{\text {coh }} \approx 200 \mathrm{~cm}^{-1}$. The spectral coherence width is approximately equal to the half-width of the spectral envelope.

Two temporal ASE pulse shapes of $2 \times 10^{-3} \mathrm{M}$ rhodamine 800 are shown in Fig. 21 $\left(I_{0 \mathrm{~L}} \approx 4 \times 10^{9} \mathrm{~W} \mathrm{~cm}^{-2}\right)$. For the smooth shape (b) all ASE light within an acceptance angle of $6^{\circ}$ is focused to the streak-camera slit. The structured curve (a) is obtained by reducing the acceptance angle to $0.08^{\circ}$. The time resolution of the streak camera is approximately $5 \mathrm{ps}$. The observed temporal structure is of the same value. A finer modulation according to the coherence duration is expected. The signal rises steeply. The maximum is reached towards the end of the pump pulse. After a rapid decline of the ASE signal, the decay changes over to the relaxation due to spontaneous emission.

The amplification of the spontaneous emission is influenced by the dye concentration. Higher dye concentrations shift the emission to longer wavelengths because of reabsorption 


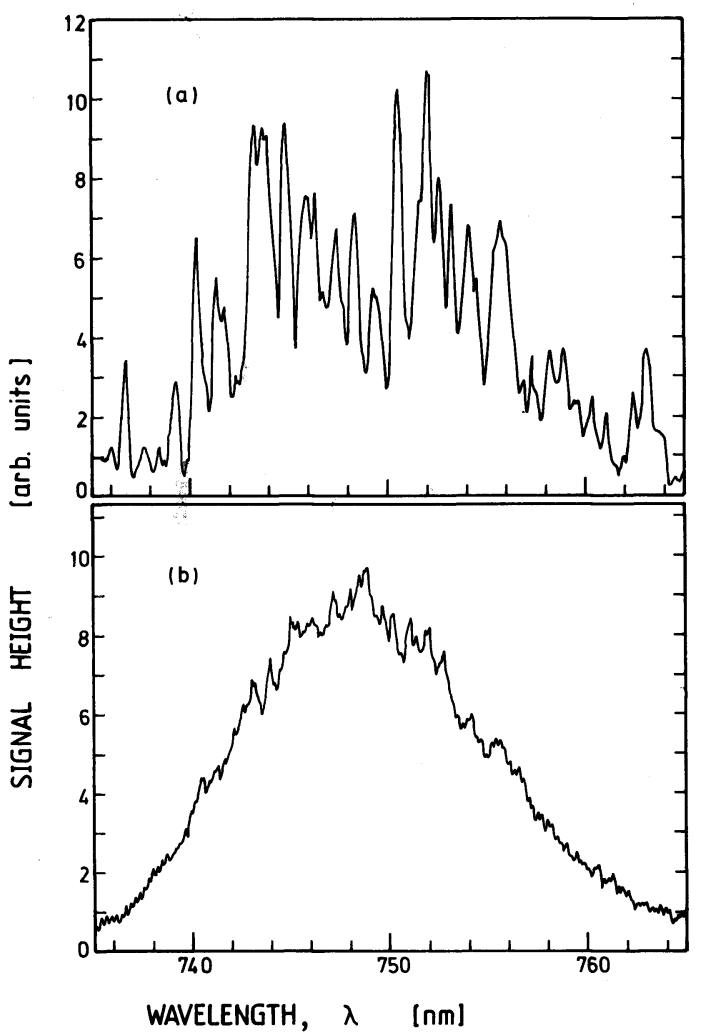

Figure 20 Spectral distribution of ASE signal behind generator cell. Dye is $10^{-4} \mathrm{M} \mathrm{DDI}$ in methanol. Input peak intensity is $I_{\mathrm{OL}} \approx 4 \times$ $10^{9} \mathrm{~W} \mathrm{~cm}^{-2}$. (a) Emission within an aperture angle of $0.08^{\circ}$. (b) Emission is collected within an angle of $6^{\circ}$.

of the short-wavelength emission. The spectral conversion efficiency $\eta_{\text {ASE }}(\lambda)$ is enlarged at the longer wavelengths, since the stimulated emission is restricted to this range (no experimental curves are shown in Figs 8 and 9; the long broken curves are calculated for $3.7 \times 10^{-5} \mathrm{M}(4)$ and $5 \times 10^{-4} \mathrm{M}\left(4^{\prime}\right)$ IR 140 , see below).

With increasing dye concentration the penetration depth of the pump pulse reduces. The excited-state absorption sets an upper limit to the penetration depth at high pump pulse intensities $\left(l_{\mathrm{eff}, \max }=\left(\sigma_{\mathrm{ex}}^{\mathrm{L}} N_{0}\right)^{-1}\right)$. Decreasing penetration depths increase the divergence angle (Equation 4). The shift of the emission to longer wavelengths lowers the stimulated emission cross-section and reduces the energy conversion efficiency $\eta_{\mathrm{ASE}}$. For highly concentrated dyes the penetration depth may become shorter than the pump beam diameter, and stimulated emission in the transverse direction may be preferred [32]. Transverse amplified spontaneous emission is facilitated by focusing the pump pulse with a cylindrical lens to the sample [5-9].

\subsection{ASE light amplification}

The efficiency of ASE saturates at high pump pulse intensities because of excited-state absorption [10]. The splitting of the pump pulse in order to pump the generator cell and several amplifier cells (here two cells, Fig. 10) avoids the efficiency reduction by excited-state absorption. Additionally, the spacing between the generator cell and the amplifier cells reduces the beam divergence.

The output beam divergence, $\Delta \Theta_{\text {out }}$, of an amplifier is related to the input beam 


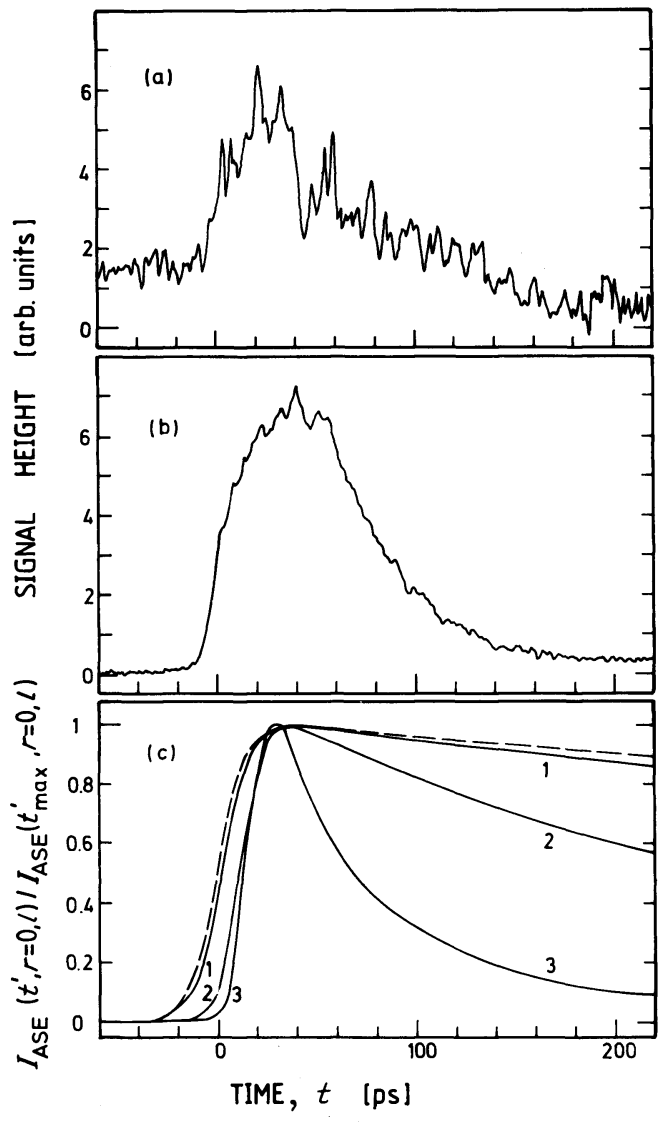

Figure 21 Temporal shapes of ASE signal behind generator cell. Dye is $2 \times 10^{-3} \mathrm{M}$ rhodamine 800 in methanol. Input peak intensity is $I_{0 L} \approx 4 \times$ $10^{9} \mathrm{~W} \mathrm{~cm}^{-2}$. (a) Observation angle is limited to $0.08^{\circ}$. (b) Emission is collected within an angle of $6^{\circ}$. (c) Calculated signals for $I_{0 L} \rightarrow 0$ (broken curve, spontaneous emission), $I_{0 \mathrm{~L}}=2 \times 10^{8} \mathrm{Wcm}^{-2}$ (1), $I_{\mathrm{OL}}=10^{9} \mathrm{Wcm}^{-2}(2)$, and $I_{\mathrm{oL}}=6 \times 10^{9} \mathrm{Wcm}^{-2}$ (3).

divergence, $\Delta \Theta_{\text {in }}$, by

$$
\Delta \Theta_{\text {out }} \approx \begin{cases}\Delta \Theta_{\text {in }} \kappa\left(G_{0}\right) \min \left(\frac{d}{d_{\text {in }}}, 1\right) & \text { for } G_{0} \geqslant 3 \\ \Delta \Theta_{\text {in }}\left[1-\frac{G_{0}-1}{2}\left(1-\frac{d}{d_{\text {in }}}\right)\right] & \text { for } 1<G_{0}<3 \\ \Delta \Theta_{\text {in }} & \text { for } G_{0} \leqslant 1\end{cases}
$$

where $d$ is the pump beam diameter at the amplifier under consideration and $d_{\text {in }}$ is the beam diameter of the input radiation at the amplifier. For the uncollimated ASE amplification in the amplifier $\mathrm{A} 1, \Delta \Theta_{\text {in }}$ is given by $\Delta \Theta_{\mathrm{ASE}}$ and the input beam diameter is $d_{\mathrm{in}}=\Delta \Theta_{\mathrm{ASE}} l_{\mathrm{GAl}}$, where $l_{\mathrm{GAl}}$ is the distance between the generator cell and the first amplifier cell. $\kappa\left(G_{0}\right)$ is the gain narrowing factor of the amplifier (Equation 5).

The effective energy conversion efficiency, $\eta_{\mathrm{AMP}}=W_{\mathrm{AMP}} / W_{\mathrm{L}}$, is included in Figs 11 to 16 for the various dye solutions. $W_{\mathrm{AMP}}$ is the generated pulse energy behind the second amplifier. $W_{\mathrm{L}}$ is the pump pulse energy before the generator cell. The filled circles denote the uncollimated propagation (without lens L4) and the triangles the collimated case. The collimation enhances the effective energy conversion efficiency $\eta_{\text {AMP }}$. At high pump intensities the amplifier gain saturates. $\eta_{\mathrm{AMP}}$ values between 0.3 and 0.8 were obtained.

The spectral efficiency distributions $\eta_{\mathrm{AMP}}(\lambda)=\left(\partial W_{\mathrm{AMP}} / \partial \lambda\right) / W_{\mathrm{L}}\left(\int_{\mathrm{em}} \eta_{\mathrm{AMP}}(\lambda) \mathrm{d} \lambda=\eta_{\mathrm{AMP}}\right)$ are 
depicted in Figs 8 and 9 (broken curves, collimated ASE, $I_{0 \mathrm{~L}} \approx 4 \times 10^{9} \mathrm{~W} \mathrm{~cm}^{-2}$ ). The spectral peak positions are practically unchanged by the amplification. The spectral widths are slightly narrowed. Curves $2\left(7.7 \times 10^{-5} \mathrm{M}\right.$ HITCI $), 2^{\prime}\left(5.6 \times 10^{-4} \mathrm{M}\right.$ HITCI $), 4$ $\left(3.7 \times 10^{-5} \mathrm{M}\right.$ IR 140) and $4^{\prime}\left(5 \times 10^{-4} \mathrm{M}\right.$ IR 140) illustrate the concentration dependence.

The pulse durations of the amplified signals, $\Delta t_{\mathrm{AMP}}^{\mathrm{ASE}}$, are listed in Table I (collimated ASE, $I_{0 \mathrm{~L}} \approx 4 \times 10^{9} \mathrm{~W} \mathrm{~cm}^{-2}$ ). They are nearly equal to the pump pulse duration. In Fig. 18 the triangles indicate the $\Delta t_{\mathrm{AMP}}^{\mathrm{ASE}}$ of the rhodamine 800 generator-amplifier chain. The collimated pulses give slightly shorter durations (filled triangle).

The pulse divergence behind the second amplifier ranges between 2 and 3 mrad (beam diameter $d \approx 0.8 \mathrm{~mm}$, distance $l_{\mathrm{GA} 2}=33 \mathrm{~cm}$ ). The beam divergence behind the second amplifer versus pump pulse peak intensity is illustrated in Fig. 19 for DDI (filled circles).

The spectral light distributions behind the amplifiers are similar to the spectra behind the generator cell. A smooth curve similar to Fig. 20b was obtained for the collimated ASE radiation. A structured curve similar to Fig. 20a is observed without collimation.

The temporal shapes of the radiation are somewhat smoothed by the amplification. The collimated radiation looks similar to Fig. 21b. A slight temporal structure is resolved for the uncollimated radiation.

\subsection{Seeding pulse amplification}

A picosecond light continuum was generated in the ruby amplifier by focusing the picosecond ruby laser pulses into the amplifer with a lens of focal length $2.5 \mathrm{~m}$ (distance from ruby rod $2 \mathrm{~m}$, double light passage through amplifier). The same experimental arrangement was used in [10]. The normalized spectral radiation intensity, $\bar{\eta}_{\mathrm{c}}(\lambda)=\left(\partial W_{\mathrm{c}} / \partial \lambda\right) / W_{\mathrm{L}} \Delta t_{\mathrm{c}} \Delta \Omega_{\mathrm{c}}$, of the generated continuum is plotted in Fig. 22 (circles and broken curves), where $W_{\mathrm{c}}$ is the energy of the picosecond continuum and $W_{\mathrm{L}}$ is the energy of the amplified ruby pulses ( $W_{\mathrm{L}} \approx 3 \mathrm{~mJ}$ in Fig. 22). The duration of the picosecond continuum $\Delta t_{\mathrm{c}}$ is approximately half the ruby pulse duration [18]. $\Delta \Omega_{\mathrm{c}}$ (FWHM) is the solid angle of efficient picosecond continuum emission $\left(\Delta \Omega_{\mathrm{c}} \approx 1 \times 10^{-4} \mathrm{sr}\right.$, divergence angle $\left.\Delta \Theta_{\mathrm{c}} \approx 1.2 \times 10^{-2} \mathrm{rad}\right)$.

The picosecond light continuum enters the generator cell simultaneously with the pump pulse. The amplification of the picosecond continuum (seeding pulse) competes with the amplification of spontaneous emission. The normalized spectral radiation intensities of the spontaneous emission in the forward direction, $\bar{\eta}_{\mathrm{F} 1}(\lambda)=\left(\partial W_{\mathrm{F} 1} / \partial \lambda\right) / W_{\mathrm{L}} \tau_{\mathrm{F}} \Delta \Omega^{\prime} \approx$ $\beta(\lambda) \tilde{E}(\lambda) / \tau_{\text {rad }} 4 \pi$ (see Equation 3), are depicted in Fig. 22 (solid curves). For all investigated dyes it is $\bar{\eta}_{\mathrm{c}}>100 \bar{\eta}_{\mathrm{Fl}}$. The spectral reflectivity of the mirrors M1 and M2 is approximately $10 \%$ for the light continua. The spectral intensity of the continua entering the generator cell is approximately a factor of 10 more intense than the generated spontaneous emission signal. The seeding pulse amplification dominated over the amplification of spontaneous emission within the small divergence angle $\Delta \Omega_{\mathrm{SPA}}$ of the amplified seeding pulse. Generally, the amplification of an input signal at a wavelength $\lambda$ dominates over the amplification of spontaneous emission at the same wavelength if $\bar{\eta}_{\mathrm{c}}(\lambda) R_{1}(\lambda)>\bar{\eta}_{\mathrm{Fl}}(\lambda)\left(1-G_{0}^{-1}\right) / \ln \left(G_{0}\right)$ (see Equation 11 [10]).

The divergence angle, $\Delta \Theta_{\mathrm{SPA}}$, of the amplified seeding pulse behind the generator is given by Equation 6 with $\Delta \Theta_{\text {out }}=\Delta \Theta_{\text {SPA }}$ and $\Delta \Theta_{\text {in }}=\Delta \Theta_{\mathrm{c}}$. The amplified seeding pulses follow any divergence changes of the picosecond continuum by focusing or defocusing. Outside $\Delta \Theta_{\mathrm{SPA}}$ the light generation is governed by amplified spontaneous emission. The angular distribution of the signal behind the generator cell is illustrated in Fig. 4 of [10]. The divergence angle $\Delta \Theta_{\mathrm{SPA}}$ versus the pump pulse peak intensity is depicted in Fig. 19 for 


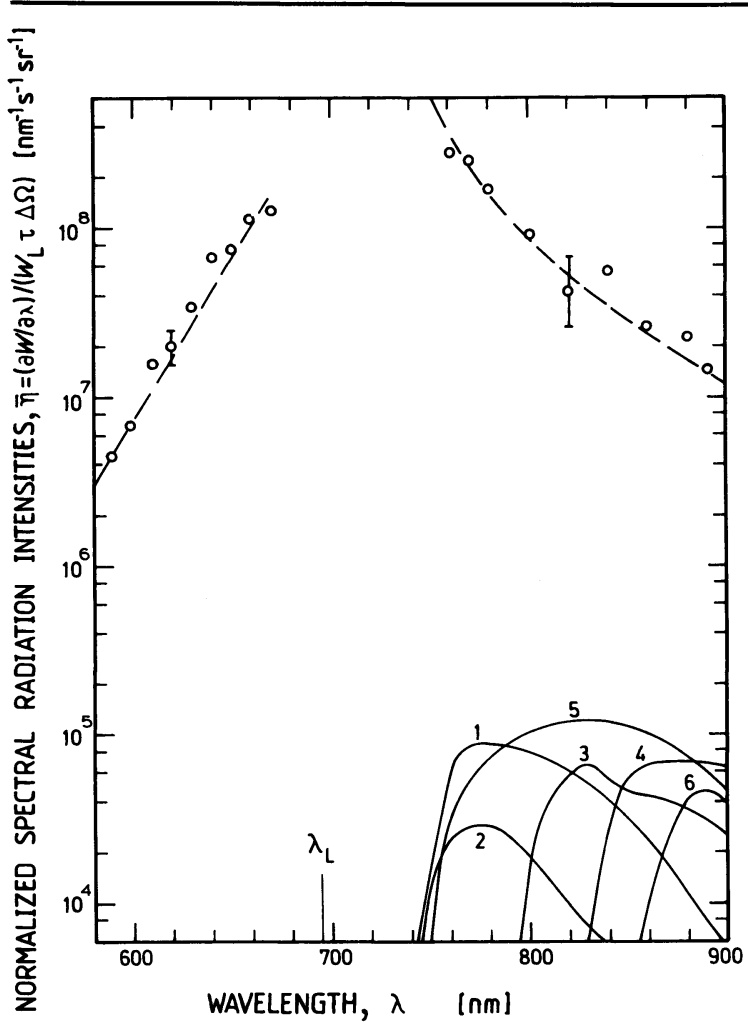

Figure 22 Comparison of the spectral radiation intensities of the seeding pulse and the spontaneous emission. Broken curves, normalized spectral radiation intensity $\bar{\eta}_{\mathrm{c}}=$ $\left(\partial W_{\mathrm{c}} / \partial \lambda\right) / W_{\mathrm{L}} \Delta t_{\mathrm{c}} \Delta \Omega_{\mathrm{c}}$ of picosecond light continuum generated in ruby amplifier. Full curves, normalized spectral radiation intensity, $\quad \bar{\eta}_{\mathrm{FI}}=\left(\partial W_{\mathrm{Fl}} / \partial \lambda\right) / W_{\mathrm{L}} \tau_{\mathrm{F}} \Delta \Omega^{\prime}$, of spontaneous emission behind generator cell. (1) DDI, (2) rhodamine 800, (3) $\mathrm{HITCl}$, (4) HDITCI, (5) styril 9, (6) IR 140.

the $10^{-4} \mathrm{M}$ dye DDI in methanol (open triangles). The divergence angles at $I_{0 \mathrm{~L}} \approx 4 \times$ $10^{9} \mathrm{~W} \mathrm{~cm}^{-2}$ are collected in Table I.

The seeding pulse amplification is illustrated in Fig. 3 of [10]. The conversion efficiency saturates at lower absolute values because of the small divergence angle of $\Delta \Theta_{\mathrm{SPA}} \approx 1.2 \times$ $10^{-3} \mathrm{rad}$. The output signal efficiency behind the amplifiers is very similar to the amplified ASE signal.

The durations $\Delta t_{\mathrm{SPA}}$ of the amplified seeding pulses behind the generator cell are shorter than the pump pulse durations (short input pulse and gain narrowing). A temporal profile is depicted in Fig. 6b of [10] for a DDI generator cell. The seeding pulse duration behind a rhodamine 800 generator cell is indicated in Fig. 18 (open diamonds). $\Delta t_{\mathrm{SPA}}$ data are given in Table I. In the amplifier cells the pulses are slightly broadened and approach the pump pulse duration (saturation of gain, see Fig. 6 of [10] and filled diamond in Fig. 18 here).

The amplified seeding pulse spectra are strongly structured. The spectra are similar to the apertured ASE spectrum of Fig. 20a. The picosecond light continuum starts from quantum fluctuations and is expected to be spectrally structured [18]. The seeding pulse amplification in the generator cell mainly preserves the structure. The spectral structure is slightly smoothed in the amplifier cells (Fig. 5 of [10]).

\section{Theoretical analysis}

\subsection{Equation system}

The longitudinal amplification of spontaneous emission (ASE), the light amplification in longitudinally pumped amplifiers (AMP) and the seeding pulse amplification (SPA) are studied theoretically. The generated light is indicated by the index GEN. 


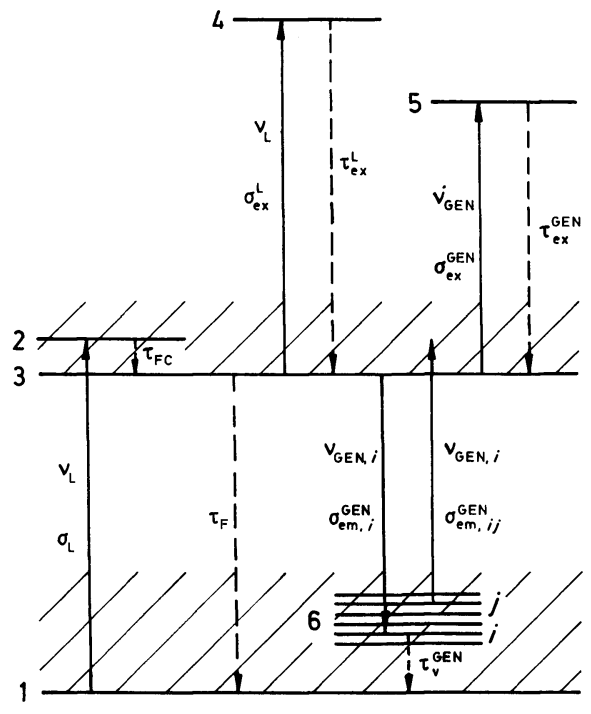

(a)

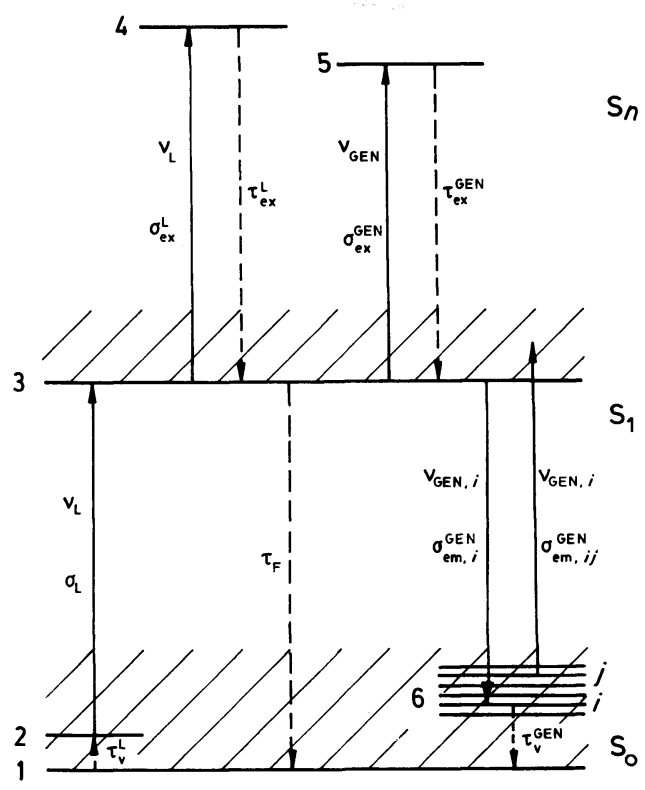

(b)

Figure 23 Energy level diagrams. (a) Laser excitation to the short-wavelength region of the $\mathrm{S}_{1}$ absorption band. (b) Laser excitation to the long-wavelength region of the $S_{1}$ absorption band.

The interaction of light with the dye molecules is illustrated by the level diagrams of Fig. 23a and b. Fig. 23a applies if the pump laser frequency $v_{\mathrm{L}}$ is higher than the frequency $v_{\mathrm{S}_{1}}$ of the pure electronic $\mathrm{S}_{0}-\mathrm{S}_{1}$ transition (all investigated dyes except rhodamine 800). The level transitions of Fig. 23b apply to $v_{\mathrm{L}}<v_{\mathrm{S}_{1}}$ (rhodamine 800) [27, 28].

The transitions of Fig. 23a and b are described by Equations 8 to 18, and 11 to 13 and 15 to 22 , respectively. The transformations $t^{\prime}=t-n z / c_{0}$ and $z^{\prime}=z$ are used. $t$ is the time, $n$ the refractive index, $z$ the distance along the light-propagation direction, and $c_{0}$ the speed of light in vacuo. Only isotropic single-photon absorption is considered, i.e. the absorption anisotropy is neglected (for its inclusion see [26, 27, 33]). For the $\sigma_{\mathrm{ex}}^{\mathrm{L}}$ determination the more complex equation systems of $[33,27]$ are applied, which include the absorption anisotropy of the electric dipole interaction. The level 1 consists of the whole $S_{0}$ band, i.e. the sublevels $(6, i)$ of Fig. 23a and the levels 2 and $(6, i)$ of Fig. 23b are included.

The equation system for Fig. 23a is:

$\frac{\partial N_{1}}{\partial t^{\prime}}=-\frac{\sigma_{\mathrm{L}}\left(N_{1}-N_{2}\right)}{h v_{\mathrm{L}}} I_{\mathrm{L}}+\sum_{i=1}^{m} \frac{1}{h v_{\mathrm{GEN}, i}}\left[\sigma_{\mathrm{em}, i}^{\mathrm{GEN}}\left(N_{3}-N_{6, i}\right)-\sum_{j=i+1}^{m} \sigma_{\mathrm{em}, i j}^{\mathrm{GEN}} N_{6, j}\right] I_{\mathrm{GEN}, i}+\frac{1}{\tau_{\mathrm{F}}} N_{3}$

$\frac{\partial N_{2}}{\partial t^{\prime}}=\frac{\sigma_{\mathrm{L}}\left(N_{1}-N_{2}\right)}{h v_{\mathrm{L}}} I_{\mathrm{L}}-\frac{N_{2}}{\tau_{\mathrm{FC}}}$

$\frac{\partial N_{3}}{\partial t^{\prime}}=\frac{N_{2}}{\tau_{\mathrm{FC}}}-\frac{\sigma_{\mathrm{ex}}^{\mathrm{L}}\left(N_{3}-N_{4}\right)}{h v_{\mathrm{L}}} I_{\mathrm{L}}-\frac{\sigma_{\mathrm{ex}}^{\mathrm{GEN}}\left(N_{3}-N_{5}\right)}{h v_{\mathrm{L}}} I_{\mathrm{GEN}}-\sum_{i=1}^{m} \frac{1}{h v_{\mathrm{GEN}, i}}$

$\times\left[\sigma_{\mathrm{em}, i}^{\mathrm{GEN}}\left(N_{3}-N_{6, i}\right)-\sum_{j=i+1}^{m} \sigma_{\mathrm{em}, i j}^{\mathrm{GEN}} N_{6, j}\right] I_{\mathrm{GEN}, i}-\frac{N_{3}}{\tau_{\mathrm{F}}}+\frac{N_{4}}{\tau_{\mathrm{ex}}^{\mathrm{L}}}+\frac{N_{5}}{\tau_{\mathrm{ex}}^{\mathrm{GEN}}}$ 


$$
\begin{aligned}
\frac{\partial N_{4}}{\partial t^{\prime}}= & \frac{\sigma_{\mathrm{ex}}^{\mathrm{L}}\left(N_{3}-N_{4}\right)}{h v_{\mathrm{L}}} I_{\mathrm{L}}-\frac{N_{4}}{\tau_{\mathrm{ex}}^{\mathrm{L}}} \\
\frac{\partial N_{5}}{\partial t^{\prime}}= & \frac{\sigma_{\mathrm{ex}}^{\mathrm{GEN}}\left(N_{3}-N_{5}\right)}{h v_{\mathrm{GEN}}} I_{\mathrm{GEN}}-\frac{N_{5}}{\tau_{\mathrm{ex}}^{\mathrm{GEN}}} \\
\frac{\partial N_{6, i}}{\partial t^{\prime}}= & \frac{e_{6, i}}{\tau_{\mathrm{rad}}} N_{3}+\frac{1}{h v_{\mathrm{GEN}, i}} \sigma_{\mathrm{em}, i}^{\mathrm{GEN}}\left(N_{3}-N_{6, i}\right) I_{\mathrm{GEN}, i} \\
\frac{\partial I_{\mathrm{L}}}{\partial z^{\prime}}= & -N_{6, i} \sum_{j=1}^{i-1} \frac{1}{h v_{\mathrm{GEN}, j}} \sigma_{\mathrm{em}, i j}^{\mathrm{GEN}} I_{\mathrm{GEN}, j}-\frac{N_{6, i}-\varrho_{6, i} N_{1}}{\tau_{\mathrm{v}}^{\mathrm{GEN}}} \\
\frac{\partial I_{\mathrm{ASE}, i}}{\partial z^{\prime}}= & \frac{e_{6, i}}{\tau_{\mathrm{rad}}} N_{3} h v_{\mathrm{GEN}, i} \frac{d^{2}}{16 l_{\mathrm{eff}}^{2}}+\left[I_{\mathrm{L}, i}^{\mathrm{GEN}}\left(N_{3}-N_{6, i}\right)-\sum_{j=i+1}^{\mathrm{L}}\left(N_{3}-N_{4}\right) I_{\mathrm{L} \mathrm{L}, i j}\right. \\
& \left.-\sigma_{\mathrm{ex}}^{\mathrm{GEN}}\left(N_{3}-N_{5}\right) I_{\mathrm{ASE}, i}\right] I_{\mathrm{ASE}, i} \\
\frac{\partial I_{\mathrm{AMP}, i}}{\partial z^{\prime}}= & {\left[\sigma_{\mathrm{em}, i}^{\mathrm{GEN}}\left(N_{3}-N_{6, i}\right)-\sum_{j=i+1}^{m} \sigma_{\mathrm{em}, i j}^{\mathrm{GEN}} N_{6, j}\right] I_{\mathrm{AMP}, i}-\sigma_{\mathrm{ex}}^{\mathrm{GEN}}\left(N_{3}-N_{5}\right) I_{\mathrm{AMP}, i} } \\
I_{\mathrm{GEN}, i}= & I_{\mathrm{ASE}, i}+I_{\mathrm{AMP}, i} \\
I_{\mathrm{GEN}}= & \sum_{i=1}^{m} I_{\mathrm{GEN}, i}
\end{aligned}
$$

The equations relevant to the level system of Fig. 23b are Equations 11 to 13,15 to 18 and the following Equations 19 to 22 .

$$
\begin{aligned}
\frac{\partial N_{1}}{\partial t^{\prime}}= & -\frac{\sigma_{\mathrm{L}}\left(N_{\hat{2}}-N_{3}\right)}{h v_{\mathrm{L}}} I_{\mathrm{L}} \\
& +\sum_{i=1}^{m} \frac{1}{h v_{\mathrm{GEN}, i}}\left[\sigma_{\mathrm{em}, i}^{\mathrm{GEN}}\left(N_{3}-N_{6, i}\right)-\sum_{j=i+1}^{m} \sigma_{\mathrm{em}, i j}^{\mathrm{GEN}} N_{6, j}\right] I_{\mathrm{GEN}, i}+\frac{N_{3}}{\tau_{\mathrm{F}}} \\
\frac{\partial N_{\hat{2}}}{\partial t^{\prime}}= & \frac{\sigma_{\mathrm{L}}\left(N_{\hat{2}}-N_{3}\right)}{h v_{\mathrm{L}}} I_{\mathrm{L}}-\frac{N_{\hat{2}}-\varrho_{\hat{2}} N_{1}}{\tau_{\mathrm{v}}^{\mathrm{L}}} \\
\frac{\partial N_{3}}{\partial t^{\prime}}= & \frac{\sigma_{\mathrm{L}}\left(N_{\hat{z}}-N_{3}\right)}{h v_{\mathrm{L}}} I_{\mathrm{L}}-\frac{\sigma_{\mathrm{ex}}^{\mathrm{L}}\left(N_{3}-N_{4}\right)}{h v_{\mathrm{L}}} I_{\mathrm{L}}-\frac{\sigma_{\mathrm{ex}}^{\mathrm{GEN}}\left(N_{3}-N_{5}\right)}{h v_{\mathrm{GEN}}} I_{\mathrm{GEN}} \\
& -\sum_{i=1}^{m} \frac{1}{h v_{\mathrm{GEN}, i}}\left[\sigma_{\mathrm{em}, i}^{\mathrm{GEN}}\left(N_{3}-N_{6, i}\right)-\sum_{j=i+1}^{m} \sigma_{\mathrm{em}, i j}^{\mathrm{GEN}} N_{6, j}\right] I_{\mathrm{GEN}, i}-\frac{N_{3}}{\tau_{\mathrm{F}}}+\frac{N_{4}}{\tau_{\mathrm{ex}}^{\mathrm{L}}}+\frac{N_{5}}{\tau_{\mathrm{ex}}^{\mathrm{GEN}}} \\
\frac{\partial I_{\mathrm{L}}}{\partial z^{\prime}}= & -\sigma_{\mathrm{L}}\left(N_{\hat{2}}-N_{3}\right) I_{\mathrm{L}}-\sigma_{\mathrm{ex}}^{\mathrm{L}}\left(N_{3}-N_{4}\right) I_{\mathrm{L}}
\end{aligned}
$$

The initial conditions for the number densities (dimension $\mathrm{cm}^{-3}$ ) of the level populations are $N_{1}\left(t^{\prime}=-\infty, r, z\right)=N_{0}, N_{2}(-\infty)=N_{3}(-\infty)=N_{4}(-\infty)=N_{5}(-\infty)=0$, 
$N_{\hat{2}}(-\infty)=\varrho_{\hat{2}} N_{0}, N_{6, i}(-\infty)=\varrho_{6, i} N_{0} . \varrho_{\hat{2}}$ and $\varrho_{6, i}$ are the occupation probabilities of the levels 2 and $6, i(i=1$ to $m)$. The initial pump pulse intensity is $I_{\mathrm{L}}\left(t^{\prime}, r, z=0\right)=I_{0 \mathrm{~L}} \times$ $\exp \left(-t^{\prime 2} / t_{0}^{2}-r^{2} / r_{0}^{2}\right) \cdot t_{0}=\Delta t_{\mathrm{L}} / 2[\ln (2)]^{1 / 2}$ is half the $1 / e$ pulse width of the pump pulse $\left(\Delta t_{\mathrm{L}}\right.$ FWHM). $r_{0}$ is the $1 / e$ beam radius of the pump pulse. The initial condition of the amplified spontaneous emission is $I_{\mathrm{ASE}, i}\left(t^{\prime}, r, z=0\right)=0$ (backward emission is not considered). $I_{\mathrm{AMP}, i}(t, r, z=0)$ is zero for pure amplified spontaneous emission in the generator cell. It is equal to the seeding pulse intensity in the case of picosecond continuum amplification in the generator cell. For the dye laser amplifiers $\mathrm{A} 1$ and $\mathrm{A} 2, I_{\mathrm{AMP}, i}\left(t^{\prime}, r, z=0\right)$ represents the input signal to the amplifiers.

Equation 8 describes the depopulation of the $\mathrm{S}_{0}$ band by single-photon absorption (first term), the refilling of the band by amplified spontaneous emission or input light amplification (first part of second term), the depopulation by reabsorption of generated light (last part of second term), and $\mathrm{S}_{1}$ band relaxation to the ground state (last term). The reabsorption cross-sections $\sigma_{\mathrm{em}, i j}^{\mathrm{GEN}}$ for the generated light at frequency $v_{\mathrm{GEN}, i}$ from the sublevels $(6, j)$ $\left(j=i+1\right.$ to $m$ ) to the $\mathrm{S}_{1}$ band are unknown. In the calculations $\Sigma_{j=i+1}^{m} \sigma_{\mathrm{em}, i j}^{\mathrm{GEN}} N_{6, j}$ is approximated by the reabsorption term $\sigma_{\mathrm{abs}, i}\left(N_{1}-N_{6, i}\right)$. Equation 9 gives the laser excitation of the Franck-Condon level 2 in the $S_{1}$ band and its radiationless relaxation to the temporal equilibrium level 3 in the $S_{1}$ band. Equation 10 handles the $S_{1}$ state dynamics, including level population (first term), excited-state absorption (second and third terms), amplified spontaneous emission or input light amplification together with reabsorption (fourth term), and relaxations (last three terms). The population of higher-lying singlet states $S_{n}$ by excited-state absorption is treated by Equations 11 and 12 . The terminal laser band 6 is subdivided into $m$ sublevels of spectral widths $\Delta v_{6, i}\left(h \Delta v_{6, i} \approx k T\right.$ is used in the calculations, the relaxed population of the $S_{1}$ band has a spectral width of approximately $\left.k T / h\right)$. The population dynamics of the sublevels $(6, i)$ is described by Equation 13 . The first term gives the contribution of the spontaneous emission. $e_{6, i}=\tilde{E}\left(v_{\mathrm{GEN}, i}\right) \Delta v_{6, i}$ is the fraction of fluorescence light which is emitted in the frequency interval $\Delta v_{6, i}$ around the frequency $v_{\mathrm{GEN}, i}$. The second term represents the light amplification. The third term, which takes care of reabsorption of the generated short-wavelength light $(j=1$ to $i-1)$, is neglected in the calculations. The last term causes thermalization within the $\mathrm{S}_{0}$ band with a time constant $\tau_{\mathrm{v}}^{\mathrm{GEN}} \cdot \varrho_{6, i}$ is approximately given by $\varrho_{6, i}=N_{6, i} / N_{1} \approx \int_{v_{6, i}^{0}}^{v_{6, i}^{0}+\Delta v_{6, i}} \exp (-h v / k T) \mathrm{d} v / \int_{0}^{\infty} \exp (-h v / k T) \mathrm{d} v=$ $\exp \left[-h v_{6, i}^{0} / k T\right]-\exp \left[-h\left(v_{6, i}^{0}+\Delta v_{6, i}\right) / k T\right] \approx\left(h \Delta v_{6, i} / k T\right) \exp \left[-h v_{6, i}^{0} / k T\right] . v_{6, i}^{0}$ is the frequency difference between the level $(6, i)$ and the $\mathrm{S}_{0}$ ground level.

The pump laser intensity reduction along the dye cells (Equation 14) is due to $S_{0}-S_{1}$ ground-state absorption (first term) and $\mathrm{S}_{1}-\mathrm{S}_{n}$ excited-state absorption (last term). The amplification of the spontaneous emission is determined by Equation 15. The first term describes the spontaneous emission, the second term gives the light amplification and takes care of reabsorption of light. The last term is due to excited-state absorption. $d^{2} /\left(16 l_{\text {eff }}^{2}\right)=$ $\Delta \Omega_{\mathrm{sp}} / 4 \pi$ is the fraction of fluorescence light emitted in the forward direction within the solid angle $\Delta \Omega_{\mathrm{sp}}$. $d$ is the pump beam diameter (FWHM). The effective interaction length is approximated by $l_{\text {eff }} \approx \min \left[l,\left(\sigma_{\mathrm{ex}}^{\mathrm{L}} N_{0}\right)^{-1}\right] . l$ is the length of the dye cell. A more rigorous treatment of the spontaneous emission in the forward direction would require the application of the Kirchhoff diffraction theory to the electric field strength of the spontaneous emission $[34,35]$. The amplification of an input signal entering the generator cell (seeding pulse amplification) and the light amplification in the amplifier cells are handled by Equation 16. The first two terms represent the amplification and the reabsorption, whereas the third term gives the excited-state absorption. The generated output signal is the sum of the ASE signal and the amplified input signal (Equations 17 and 18). 
The long-wavelength excitation of the $S_{1}$ band causes some changes [27, 28]. The level transitions are shown in Fig. 23b. Equation 19 gives the modified dynamics of the total population of the $S_{0}$ band. The first term is different from the corresponding term in Equation 8. It considers the $S_{0}-S_{1}$ absorption. The transition occurs from level 2 to level 3 . Level $\hat{2}$ resembles a subgroup of inhomogeneously broadened molecules with optimum $\mathrm{S}_{0}-\mathrm{S}_{1}$ transition frequency $v_{\mathrm{L}}$ and thermally excited molecules. The initial population density $\mathrm{N}_{\hat{2}}$ is given by $\mathrm{N}_{\hat{2}}=\varrho_{\hat{2}} N_{0}$, with $\varrho_{\hat{2}} \approx \sigma_{\text {abs }}\left(v_{\mathrm{L}}\right) / \sigma_{\text {em }}\left(v_{\mathrm{L}}\right)$ [27, 28]. The absorption cross-section is given approximately by $\sigma_{\mathrm{L}} \approx \sigma_{\mathrm{em}}\left(v_{\mathrm{L}}\right)$. The population dynamics of level $\hat{2}$ is manifested by Equation 20. The first term takes care of the absorption, and the second term gives the refilling of the level by thermalization of the $S_{0}$ band with a time constant $\tau_{v}^{\mathrm{L}}$. The relaxed level 3 of the $S_{1}$ band is populated directly by the first term of Equation 21 . The other terms are the same as in the case of short-wavelength excitation (Equation 10). The pump pulse transmission through the dye sample is governed by Equation 22, containing ground-state absorption and excited-state absorption.

\subsection{Analysis of energy transmission}

The energy transmission of the pump pulses through the dye samples is given by

$$
\begin{aligned}
T_{\mathrm{E}} & =\frac{\int_{0}^{\infty} r\left[\int_{-\infty}^{\infty} I_{\mathrm{L}}\left(r, t^{\prime}, l\right) \mathrm{d} t^{\prime}\right] \mathrm{d} r}{\int_{0}^{\infty} r\left[\int_{-\infty}^{\infty} I_{\mathrm{L}}\left(r, t^{\prime}, 0\right) \mathrm{d} t^{\prime}\right] \mathrm{d} r} \\
& =\frac{2}{I_{0 \mathrm{~L}} r_{0}^{2} t_{0} \pi^{1 / 2}} \int_{0}^{\infty} r\left[\int_{-\infty}^{\infty} I_{\mathrm{L}}\left(r, t^{\prime}, l\right) \mathrm{d} t^{\prime}\right] \mathrm{d} r
\end{aligned}
$$

Energy transmission points of the investigated dyes are depicted in Fig. 7. The theoretical curves are calculated by extending Equations 8 to 14 and 19 to 21 to include the absorption anisotropy of the electric dipole interaction. The equation systems used are given in [33] (for all dyes except rhodamine 800) and [27] (for rhodamine 800). The best-fitting excited-state absorption cross-sections $\sigma_{\mathrm{ex}}^{\mathrm{L}}$ are listed in Table I and indicated in Figs 1 to 6 . The influence of the absorption anisotropy is seen by comparison of curves 1 with the broken curves (no absorption anisotropy) of Figs $7 \mathrm{~d}$ and e.

\subsection{Analysis of amplified spontaneous emission}

The solution of Equations 8 to 15 and 19 to 22 gives the spectral intensity components $I_{\mathrm{ASE}, i}\left(t^{\prime}, r=0, l\right)$ behind the generator cell. The intensity $I_{\mathrm{ASE}}\left(t^{\prime}, r=0, l\right)$ is the sum over the components. The time-integrated intensity (in $\mathrm{J} \mathrm{cm}^{-2}$ ) is $w_{\mathrm{ASE}}(r=0, l)=$ $\int_{-\infty}^{\infty} I_{\mathrm{ASE}}\left(t^{\prime}, r=0, l\right) \mathrm{d} t^{\prime}$.

The spectral energy components $w_{\mathrm{ASE}, i}$ and the total energy $W_{\mathrm{ASE}}$ for a pump pulse peak of intensity $I_{0 \mathrm{~L}}$ are obtained approximately by spatial integration over the time-integrated intensities:

$$
\begin{aligned}
W_{\mathrm{ASE}, i}\left(I_{0 \mathrm{~L}}\right) & \approx \int_{0}^{\infty} 2 \pi r \mathrm{~d} r w_{\mathrm{ASE}, i}(r) \\
W_{\mathrm{ASE}} & =\sum_{i} W_{\mathrm{ASE}, i}
\end{aligned}
$$

where $w_{\mathrm{ASE}, i}(r)$ is the time-integrated intensity of the pump pulse intensity $I_{\mathrm{L}}(r)=I_{0 \mathrm{~L}} \times$ $\exp \left(-r^{2} / r_{0}^{2}\right)$. 
The spectral conversion efficiency $\eta_{\text {ASE }}(\tilde{v})$ is

$$
\eta_{\mathrm{ASE}}(\tilde{v}) \approx \frac{1}{\Delta \tilde{v}_{6, i}} \eta_{\mathrm{ASE}, i}=\frac{1}{\Delta \tilde{v}_{6, i}} \frac{W_{\mathrm{ASE}, i}}{W_{\mathrm{L}}}
$$

where $W_{\mathrm{L}}$ is the input pump pulse energy. The energy conversion efficiency is

$$
\eta_{\mathrm{ASE}}=W_{\mathrm{ASE}} / W_{\mathrm{L}}
$$

The divergence of the ASE signal is given by Equations 4 to 6 . The calculated divergence angles $\Delta \Theta_{\mathrm{ASE}}$ agree well with the measured divergences (see curve 1 in Fig. 19; in this case $l_{\text {eff }}$ is determined by $\int_{-\infty}^{\infty} I_{\mathrm{L}}\left(r, t^{\prime}, l_{\text {eff }}\right) \mathrm{d} t^{\prime} / \int_{-\infty}^{\infty} I_{\mathrm{L}}\left(r, t^{\prime}, 0\right) \mathrm{d} t^{\prime}=e^{-1}$, see Equation 23). In Figs 11 to 16 experimental $\eta_{\text {ASE }}$ points and calculated $\eta_{\text {ASE }}$ curves are shown. The excitedstate absorption cross-sections $\sigma_{\mathrm{ex}}^{\mathrm{GEN}}$ are determined by fitting the curves to the experimental data. The $\sigma_{\mathrm{ex}}^{\mathrm{GEN}}$ values obtained are collected in Table I and included in Figs 1 to 6 . The excited-state absorption $\sigma_{\mathrm{ex}}^{\mathrm{GEN}}$ and $\sigma_{\mathrm{ex}}^{\mathrm{L}}$ reduce the conversion efficiency and lead to a decrease of $\eta_{\mathrm{ASE}}$ at high pump pulse intensities.

In Figs 8 and 9 the experimentally measured conversion efficiency distributions $\eta_{\mathrm{ASE}}(\lambda)=$ $\eta_{\text {ASE }}(\tilde{v}) / \lambda^{2}$ are shown. For IR 140 the calculated $\eta_{\text {ASE }}(\lambda)$ curves are included for dye concentrations of $3.7 \times 10^{-5} \mathrm{M}$ (long-broken curve 4) and $5 \times 10^{-4} \mathrm{M}$ (long-broken curve $4^{\prime}$ ). At the higher dye concentration the long-wavelength efficiency is increased whereas the total conversion efficiency is reduced. For $C=3.7 \times 10^{-5} \mathrm{M}$ the experimental curve and the theoretical curve agree fairly well.

In Fig. 21c calculated ASE pulse shapes are presented for the $2 \times 10^{-3} \mathrm{M}$ dye rhodamine 800. The calculated curves are normalized according to $I_{\mathrm{ASE}}\left(t^{\prime}, 0, l\right) / I_{\mathrm{ASE}}\left(t_{\max }^{\prime}, 0, l\right)$. The spontaneous emission curve is shown for comparison $\left(I_{0 \mathrm{~L}} \rightarrow 0\right.$, broken curve). The ASE pulse shortening with rising pump pulse intensity is clearly observed.

The level populations versus pump pulse peak intensity are illustrated in Fig. 24 for the dye DDI (level system of Fig. 23a). The length-integrated number densities of levels 1, 3 and $(6, i)$ are presented for $t^{\prime}=\Delta t_{\mathrm{L}} / 2=15 \mathrm{ps}$. At high pump pulse intensities the ground-state population depletes $\left(N_{1}\right)$. The $\mathrm{S}_{1}$ state population $\left(N_{3}\right)$ rises linearly with pump intensity until at high intensities the population density $N_{3}$ levels off because of amplified spontaneous emission. At low intensities the terminal ASE levels $(6, i)$ are already thermally populated. With rising pump pulse intensity the population of the levels $(6, i)$ begins to decrease since the $\mathrm{S}_{1}$ state is populated. At high intensities the population densities $N_{6, i}$ increase because of level-filling by amplified spontaneous emission and due to the finite thermalization time of the population in the $\mathrm{S}_{0}$ band (bottleneck effect). The filling of the levels $(6, i)$ saturates the gain of the ampified spontaneous emission.

\subsection{Seeding pulse and ASE light amplification}

Equations 8 to 22 can be used to calculate the light amplification in any longitudinally pumped dye laser amplifier. The temporal, spectral and spatial output characteristics of the amplified input signal and the concurrent amplified spontaneous emission may be determined.

Here we restrict ourselves to illustrating the seeding pulse amplification and the ASE light amplification by the numerical solution of instructive situations. A complete numerical simulation of all experimental seeding pulse amplifications and ASE light amplifications is not given. The spectroscopic data of $5.1 \times 10^{-5} \mathrm{M}$ HDITCI are used in the calculations (Table I). 


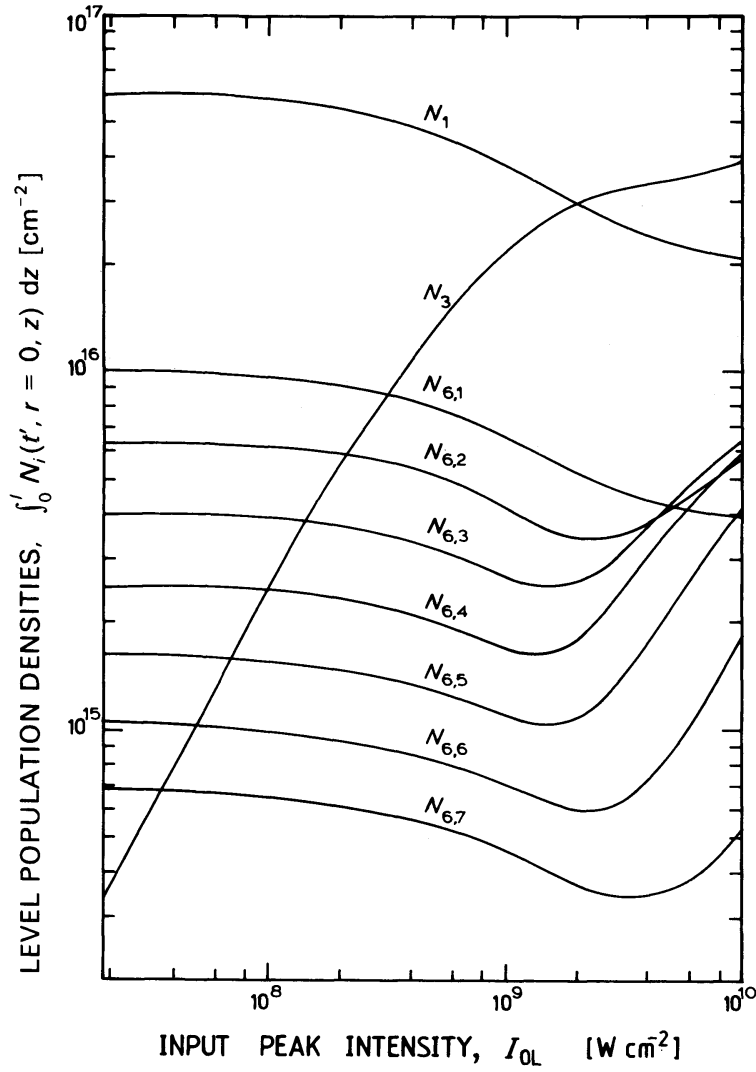

Figure 24 Length integrated level populations in generator cell. Dye is $10^{-4} \mathrm{M}$ DDI in methanol. Curves are calculated. The data of the $N_{6, i}$ curves are: $\lambda_{\text {ASE }}=730 \mathrm{~nm}$ for $i=1,735 \mathrm{~nm}$ for $i=2,740 \mathrm{~nm}$ for $i=3$, $745 \mathrm{~nm}$ for $i=4,750 \mathrm{~nm}$ for $i=5,755 \mathrm{~nm}$ for $i=6$ and $760 \mathrm{~nm}$ for $i=7$. In all cases $\Delta \lambda=5 \mathrm{~nm}$.

The input pulse amplification in a longitudinally pumped dye cell modifies the temporal output pulse shape. The temporal delay between the pump pulse and the input pulse influences the contribution of the amplified spontaneous emission. Input pulses that are short compared with the pump pulse duration are broadened, whereas input pulses that are long compared with the pump pulse are shortened. These dependences are illustrated in Figs 25 (amplification of ASE pulse) and 26 (amplification of picosecond continuum). The temporal shapes of the input pulses and the pump pulses are depicted in the lower parts (a). In (b) and (c) the pump pulse peak intensities $I_{0 \mathrm{~L}}$ and the input pulse peak intensities are varied. The broken curves represent pure amplified spontaneous emission $\left(I_{\text {in }}=0\right)$. The trailing humps in Fig. 26b and c are due to amplified spontaneous emission (thermalization of $\mathrm{S}_{0}$ band with time constant $\tau_{\mathrm{v}}^{\mathrm{GEN}}$ increases the inversion and leads to a gain recovery).

In Fig. 27 the normalized output energy $\int_{-\infty}^{\infty} I_{\text {out }}\left(t^{\prime}\right) \mathrm{d} t / \int_{-\infty}^{\infty} I_{\mathrm{L}}\left(z=0, t^{\prime}\right) \mathrm{d} t^{\prime}$ versus pump pulse peak intensity $I_{0 \mathrm{~L}}$ is depicted for $I_{\text {in }}\left(t_{\max }^{\prime}\right) / I_{0 \mathrm{~L}}=10^{-4}$ (curves 1 ) and $10^{-1}$ (curves 2). The chain-broken curves belong to the broad input signal (Fig. 25) and the solid curves belong to the short input signal (Fig. 26).

The spectral pulse development is studied in Figs 28 (amplification of broadband picosecond continuum) and 29 (amplification of spectrally narrowed radiation as needed for wavelength tuning [10]). The spectral shapes of the input pulses and the stimulated emission cross-section profiles are shown in the lower parts of the figures. The normalized spectral output $\int_{-\infty}^{\infty} I_{\text {out }}\left(\lambda, t^{\prime}\right) \mathrm{d} t^{\prime} / \int_{-\infty}^{\infty} I_{\mathrm{L}}\left(z=0, t^{\prime}\right) \mathrm{d} t^{\prime}$ for different pump pulse intensities and input 


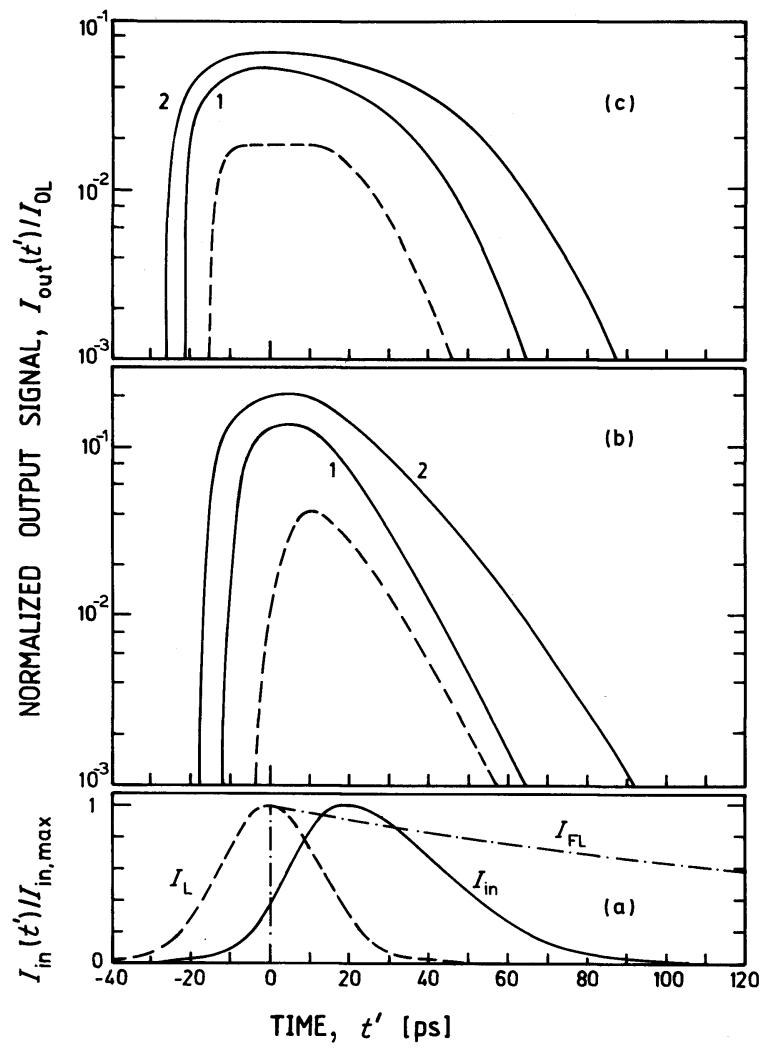

Figure 25 Temporal behaviour of ASE light amplification in amplifier cell. Dye is $5.1 \times$ $10^{-5} \mathrm{M} \mathrm{HDITCl}$ in 1:1 ethylene glycolDMSO. $l=1 \mathrm{~cm}, d=0.8 \mathrm{~mm}$. (a) Broken curve, shape of pump pulse; full curve, shape of input pulse (Gaussian rise and decay with different constants). Spectral pulse shape is assumed to be centred at $\lambda=835 \mathrm{~nm}$ with a spectral width of $\Delta \lambda=20 \mathrm{~nm}$. Chain-broken curve, decay of spontaneous emission for $\delta$-pulse excitation at time $t=0$. (b) Input pump pulse peak intensity $I_{0 \mathrm{~L}}=10^{9} \mathrm{~W} \mathrm{~cm}^{-2}$. The peak intensities of the ASE input pulses are $I_{\text {in. } 0}=0$ (broken curve), (1) $I_{\text {in }, 0}=10^{5} \mathrm{~W} \mathrm{~cm}^{-2}$, (2) $I_{\text {in, } 0}=10^{8} \mathrm{~W} \mathrm{~cm}^{-2}$. (c) $I_{0 \mathrm{~L}}=6 \times 10^{9} \mathrm{~W} \mathrm{~cm}^{-2}$. $I_{\text {in, } 0}=0$ (broken curve), (1) $I_{\text {in, } 0}=6 \times$ $10^{5} \mathrm{~W} \mathrm{~cm}^{-2}$, (2) $l_{\mathrm{in}, 0}=6 \times 10^{8} \mathrm{~W} \mathrm{~cm}^{-2}$.

pulse intensities are depicted in (b) and (c). The broken curves represent the pure amplified spontaneous emission $\left[I_{\text {in }}\left(\lambda, t^{\prime}\right)=0\right]$.

In Fig. 30 the ratio of the ASE signal to the amplified signal, $\int I_{\mathrm{ASE}}\left(l, \lambda, t^{\prime}\right) \mathrm{d} t^{\prime} \mathrm{d} \lambda /$ $\int I_{\mathrm{SIG}}\left(l, \lambda, t^{\prime}\right) \mathrm{d} t^{\prime} \mathrm{d} \lambda$ (background ratio), is depicted $\left(I_{\text {out }}=I_{\mathrm{ASE}}(l)+I_{\mathrm{SIG}}(l)\right)$. The input signal has the same shape as in Fig. $29(\Delta \lambda=1 \mathrm{~nm})$. The wavelength dependence of this background ratio indicates the dependence on $\sigma_{\mathrm{em}}(\lambda) / \sigma_{\mathrm{em} \text { max }}\left(\sigma_{\mathrm{em}}(\lambda) / \sigma_{\mathrm{em} \text {,max }}\right.$ varies over a factor of 30 in Fig. 30a). The background ratio depends on the input signal, $I_{\text {in. } 0}$, and the pump pulse, $I_{0 \mathrm{~L}}$. Curves for different $I_{\mathrm{in}, 0} / I_{0 \mathrm{~L}}$ ratios are given in Figs $30 \mathrm{~b}\left(I_{0 \mathrm{~L}}=3 \times 10^{8} \mathrm{~W} \mathrm{~cm}^{-2}\right)$ and $30 \mathrm{c}\left(I_{0 \mathrm{~L}}=6 \times 10^{9} \mathrm{~W} \mathrm{~cm}^{-2}\right)$.

The spatial pulse development is analysed in Fig. 31. The spatial distributions of the input pulse (solid curve) and the pump pulse (broken curve) are illustrated in Fig. 31a. The angular distributions of the input signal and of the pump pulse are depicted in Fig. 31b. The angular spreads of the output signals are shown in Fig. 31c. The angular spread of the ASE signal $\left(I_{\text {in }}(\theta)=0\right)$ is shown for comparison (broken curve). Equations 3 to 5 are used in the calculations.

\subsection{Additional influences}

The dye excitation causes refractive index changes that influence the spatial and temporal propagation of the pump pulse and the generated light. For the seeding pulse amplification in the generator cell and for the signal amplification in the amplifier cells Raman 


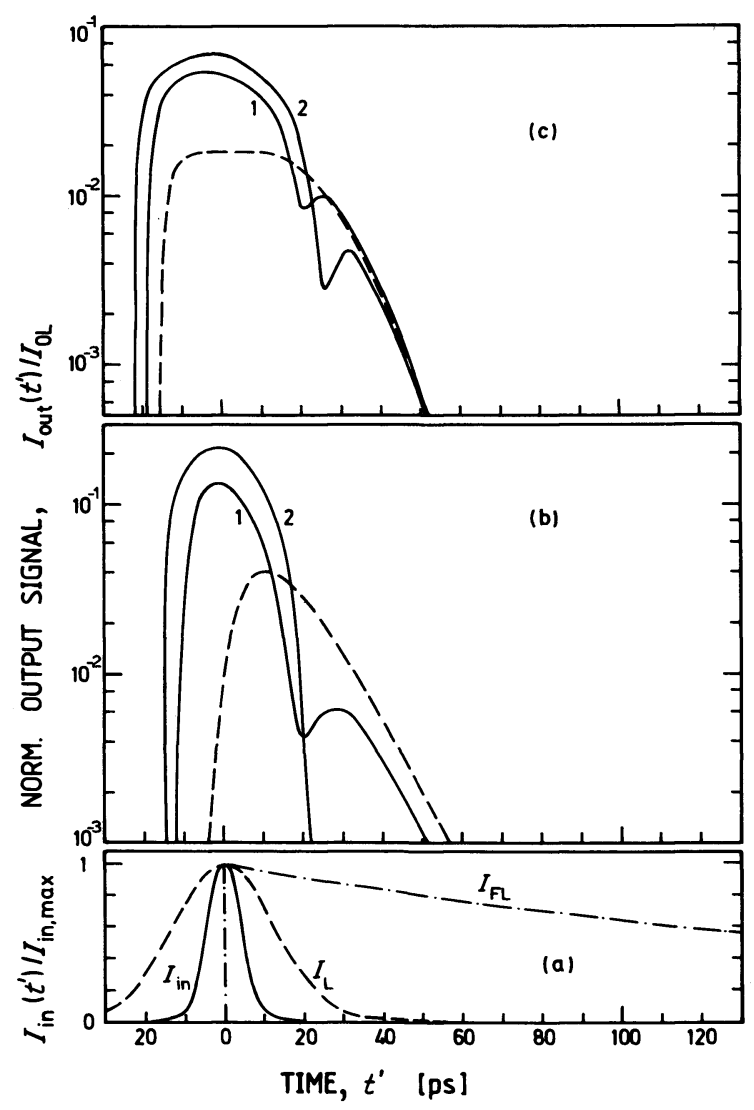

Figure 26 Temporal behaviour of seeding pulse amplification. For legend see Fig. 25. Input pulse has symmetric Gaussian shape.

amplification is observed. The amplification of input spectral components by stimulated Raman scattering is enhanced by single-photon resonances (the pump laser frequency is within the $S_{0}-S_{1}$ transition band). The spontaneous emission is an incoherent process. The picosecond light continua start from quantum fluctuations [18]. The stimulated emission gives a coherent amplification of the input signal. The amplification of spontaneous emission and of picosecond light continua leads to temporal, spectral and spatial coherence effects.

\subsubsection{Refractive index effects}

Absorbing media are characterized by a complex refractive index $\tilde{n}$. It is $\tilde{n}^{2}=(n-\mathrm{i} \kappa)^{2}=$ $n^{2}+\kappa^{2}-2 \mathrm{i} n \kappa=1+\chi=1+\chi^{\prime}-\mathrm{i} \chi^{\prime \prime}$. For dye solutions the linear susceptibility $\chi$ is composed of solvent and solute contributions, i.e. $\chi=\chi_{\mathrm{S}}+\chi_{\mathrm{D}}=\chi_{\mathrm{S}}+\chi_{\mathrm{D}}^{\prime}-\mathrm{i} \chi_{\mathrm{D}}^{\prime \prime}$. The solvent susceptibility $\chi_{\mathrm{S}}$ is real. The solvent refractive index is $n_{\mathrm{S}}=\left(1+\chi_{\mathrm{S}}\right)^{1 / 2}$. The extinction coefficient of the dye solution, $\kappa$, is small compared with $n_{\mathrm{S}}\left(\kappa \ll n_{\mathrm{S}}\right)$. Therefore the refractive index of the solution is

$$
n \approx\left(1+\chi_{\mathrm{S}}+\chi_{\mathrm{D}}^{\prime}\right)^{1 / 2} \approx n_{\mathrm{S}}+\frac{\chi_{\mathrm{D}}^{\prime}}{2 n_{\mathrm{S}}}=n_{\mathrm{S}}+\frac{N_{0} L}{2 n_{\mathrm{s}} \varepsilon_{0}} \gamma_{\mathrm{S}_{0}}^{\prime}
$$

The last equality is obtained from the relation

$$
\chi_{\mathrm{D}}=\frac{N_{0} L}{\varepsilon_{0}} \gamma_{\mathrm{S}_{0}}
$$




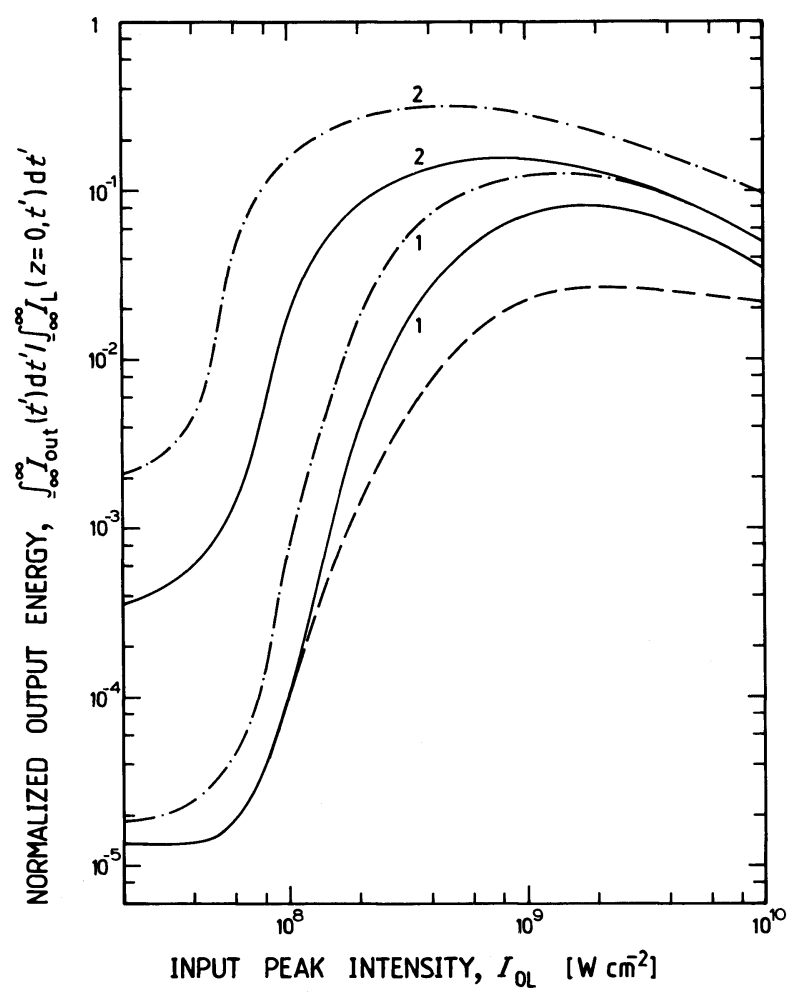

Figure 27 Normalized output energy versus pump pulse peak intensity for various input pulses. Chain-broken curves correspond to pulse shapes of Fig. 25. Full curves correspond to pulse shapes of Fig. 26. Broken curve represents amplified spontaneous emission $\left(I_{\text {in }, 0}=0\right)$. (1) $I_{\text {in }, 0} / I_{\mathrm{OL}}=10^{-4}$, (2) $I_{\text {in }, 0} /$ $I_{\mathrm{OL}}=10^{-1}$.

where $\gamma_{\mathrm{s}_{0}}$ is the linear polarizability of a dye molecule in the ground state, $L \approx\left(n_{\mathrm{S}}^{2}+2\right) / 3$ is the Lorentz local field correction factor, $N_{0}$ is the number density of dye molecules and $\varepsilon_{0}$ is the vacuum permittivity. The imaginary part of the dye susceptibility is given by [36]

$$
\chi_{\mathrm{D}}^{\prime \prime}=2 n \kappa=\frac{n \alpha}{2 \pi \tilde{v}}=\frac{n N_{0} \sigma}{2 \pi \tilde{v}}=\frac{N_{0} L}{\varepsilon_{0}} \gamma_{\mathrm{s}_{0}}^{\prime \prime}
$$

where $\alpha$ is the absorption coefficient and $\sigma$ is the absorption cross-section.

Laser excitation of dye molecules changes $\chi_{\mathrm{D}}$ to

$$
\chi_{\mathrm{D}}+\Delta \chi_{\mathrm{D}}=\frac{L}{\varepsilon_{0}}\left[\left(N_{0}-N_{3}\right) \gamma_{\mathrm{S}_{0}}+N_{3} \gamma_{\mathrm{S}_{1}}\right]=\frac{L}{\varepsilon_{0}} N_{0} \gamma_{\mathrm{s}_{0}}+\frac{L}{\varepsilon_{0}} N_{3}\left(\gamma_{\mathrm{S}_{1}}-\gamma_{\mathrm{S}_{0}}\right)
$$

where $\gamma_{s_{1}}$ is the polarizability of a dye molecule in the first excited singlet state. The refractive index change due to laser interaction is

$$
\Delta n=\Delta n_{\mathrm{S}}+\Delta n_{\mathrm{D}}=\Delta n_{\mathrm{S}}+\frac{\Delta \chi_{\mathrm{D}}^{\prime}}{2 n_{\mathrm{S}}}=\frac{n_{2}}{n_{\mathrm{S}} \varepsilon_{0} c_{0}} I_{\mathrm{L}}+\frac{L}{2 n_{\mathrm{S}} \varepsilon_{0}} N_{3}\left(\gamma_{\mathrm{S}_{1}}^{\prime}-\gamma_{\mathrm{S}_{0}}^{\prime}\right)
$$

The first term describes the refractive index change of the solvent $\left(\Delta n_{\mathrm{S}}=n_{2}\left|E_{0 \mathrm{~L}}\right|^{2} / 2\right.$; $I_{\mathrm{L}}=n_{\mathrm{S}} \varepsilon_{0} c_{0}\left|E_{0 \mathrm{~L}}\right|^{2} / 2$; a contribution of the solute to $n_{2}$ is neglected). For a crude estimate the frequency dependence of $\gamma_{\mathrm{S}_{0}}$ and $\gamma_{\mathrm{S}_{1}}$ may be approximated by [37]

$$
\gamma_{\mathrm{s}_{0}}(\tilde{v})=\frac{\gamma_{\mathrm{S}_{0}, \max }^{\prime \prime} \Delta \tilde{v}_{\mathrm{abs}} / 2}{\tilde{v}_{\mathrm{abs}}^{\max }-\tilde{v}+\mathrm{i} \Delta \tilde{v}_{\mathrm{abs}} / 2}=\frac{n_{\mathrm{s}} \varepsilon_{0} \sigma_{\mathrm{abs}}^{\max } \Delta \tilde{v}_{\mathrm{abs}}}{4 \pi \tilde{v}_{\mathrm{em}}^{\max } L} \frac{1}{\tilde{v}_{\mathrm{abs}}^{\max }-\tilde{v}+\mathrm{i} \Delta \tilde{v}_{\mathrm{abs}} / 2}
$$




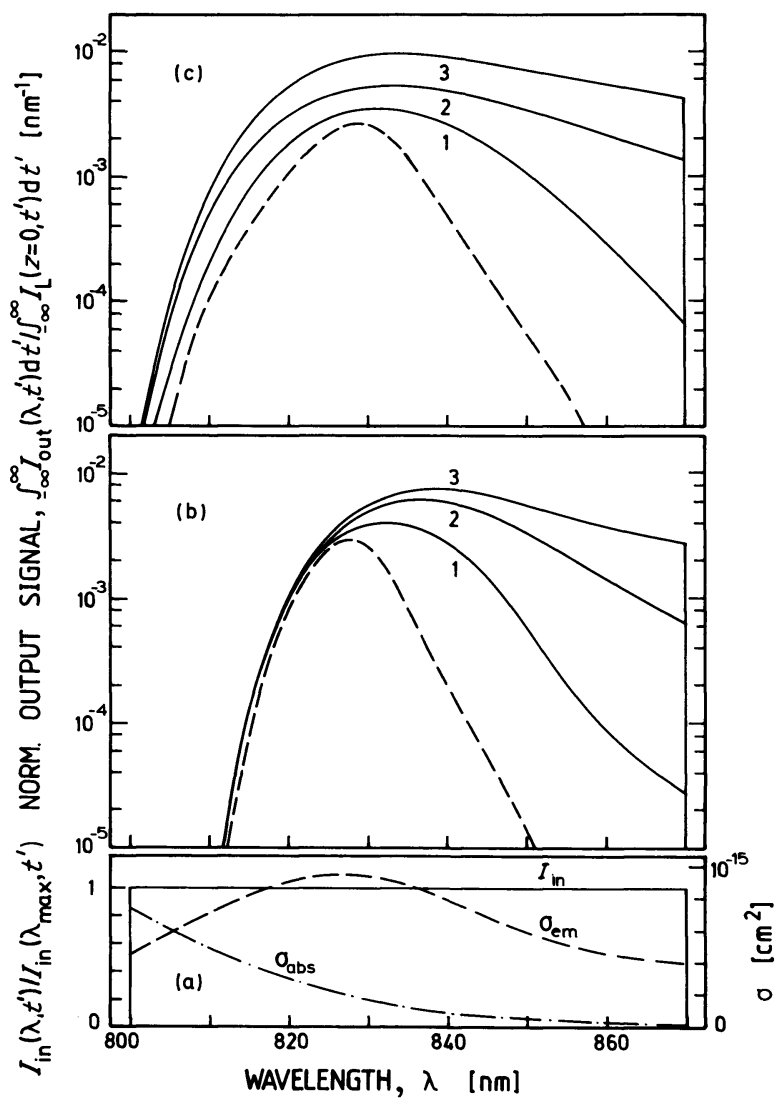

Figure 28 Spectral behaviour of broadband light amplification in amplifier cell. Dye is $5.1 \times 10^{-5} \mathrm{M} \mathrm{HDITCl}$ in $1: 1$ ethylene glycol-DMSO. Cell length $/=$ $1 \mathrm{~cm}$. Pump pulse diameter $d=0.8 \mathrm{~mm}$. (a) Full curve, spectral distribution of input signal. $I_{\text {in }}(\lambda)=I_{\text {in }, 0} / \Delta \lambda, \Delta \lambda=70 \mathrm{~nm}$. Broken curve, stimulated emission crosssection of dye. Chain-broken curve, absorption cross-section of dye. Temporal pulse shapes of pump pulse and input signal are given in Fig. 26a. (b) Input pump pulse peak intensity $I_{0 \mathrm{~L}}=10^{9} \mathrm{~W} \mathrm{~cm}^{-2}$. Broken curve, ASE signal $\left(I_{\text {in, } 0}=0\right)$; full curves, (1) $I_{\text {in }, 0}=$ $10^{5} \mathrm{~W} \mathrm{~cm}^{-2}$, (2) $l_{\text {in, } 0}=10^{7} \mathrm{~W} \mathrm{~cm}^{-2}$, (3) $I_{\text {in, } 0}=10^{8} \mathrm{~W} \mathrm{~cm}^{-2}$. (c) $I_{0 \mathrm{~L}}=6 \times$ $10^{9} \mathrm{~W} \mathrm{~cm}^{-2}$. Broken curve, ASE signal; full curves, (1) $l_{\text {in }, 0}=6 \times 10^{5} \mathrm{~W} \mathrm{~cm}^{-2}$, (2) $l_{\text {in }, 0}=6 \times 10^{7} \mathrm{Wcm}^{-2}$, (3) $l_{\text {in }, 0}=$ $6 \times 10^{8} \mathrm{~W} \mathrm{~cm}^{-2}$.

and

$$
\gamma_{\mathrm{S}_{1}}(\tilde{v})=\frac{-\left|\gamma_{\mathrm{s}_{1}, \max }^{\prime \prime}\right| \Delta \tilde{v}_{\mathrm{em}} / 2}{\tilde{v}_{\mathrm{em}}^{\max }-\tilde{v}+\mathrm{i} \Delta \tilde{v}_{\mathrm{em}} / 2}=\frac{-n_{\mathrm{S}} \varepsilon_{0} \sigma_{\mathrm{em}}^{\max } \Delta \tilde{v}_{\mathrm{em}}}{4 \pi \tilde{v}_{\mathrm{em}}^{\max } L} \frac{1}{\tilde{v}_{\mathrm{em}}^{\max }-\tilde{v}+\mathrm{i} \Delta \tilde{v}_{\mathrm{em}} / 2}
$$

where $\sigma_{\mathrm{abs}}^{\max }$ and $\sigma_{\mathrm{em}}^{\max }$ are the maxima of the $\mathrm{S}_{0}-\mathrm{S}_{1}$ absorption and emission cross-sections, respectively. $\Delta \tilde{v}_{\text {abs }}$ is the spectral width of the absorption band (FWHM) and $\Delta \tilde{v}_{\mathrm{em}}$ is the spectral width of the emission band. Forming the real parts of Equations $32 \mathrm{a}$ and $\mathrm{b}$ (see inset of Fig. 32) and inserting into Equation 31 gives

$$
\begin{aligned}
\Delta n(\tilde{v})= & \frac{n_{2}}{n_{\mathrm{S}} \varepsilon_{0} c_{0}} I_{\mathrm{L}}+\frac{N_{3}}{8 \pi}\left(\frac{\sigma_{\mathrm{em}}^{\max } \Delta \tilde{v}_{\mathrm{em}}}{\tilde{v}_{\mathrm{em}}^{\max }} \frac{\tilde{v}-\tilde{v}_{\mathrm{em}}^{\max }}{\left(\tilde{v}_{\mathrm{em}}^{\max }-\tilde{v}\right)^{2}+\left(\Delta \tilde{v}_{\mathrm{em}} / 2\right)^{2}}\right. \\
& \left.-\frac{\sigma_{\mathrm{abs}}^{\max } \Delta \tilde{v}_{\mathrm{abs}}}{\tilde{v}_{\mathrm{abs}}^{\max }} \frac{\tilde{v}_{\mathrm{abs}}^{\max }-\tilde{v}}{\left(\tilde{v}_{\mathrm{abs}}^{\max }-\tilde{v}\right)^{2}+\left(\Delta \tilde{v}_{\mathrm{em}} / 2\right)^{2}}\right)
\end{aligned}
$$

$\Delta n_{\mathrm{D}} / N_{3}$ is plotted in Fig. 32 for the various dyes investigated. The refractive index changes $\Delta n_{\mathrm{S}}$ (for $I_{\mathrm{L}}=5 \times 10^{9} \mathrm{~W} \mathrm{~cm}^{-2}$ ) and $\Delta n_{\mathrm{D}}^{\max }\left(N_{3}=N_{0}\right)$ at the pump laser frequency $v_{\mathrm{L}}$ are listed in Table II.

The spatial refractive index variation across the beam profile may lead to self-focusing of the pump pulse $(\Delta n>0)$ and to focusing $(\Delta n>0)$ or defocusing $(\Delta n<0)$ of the 


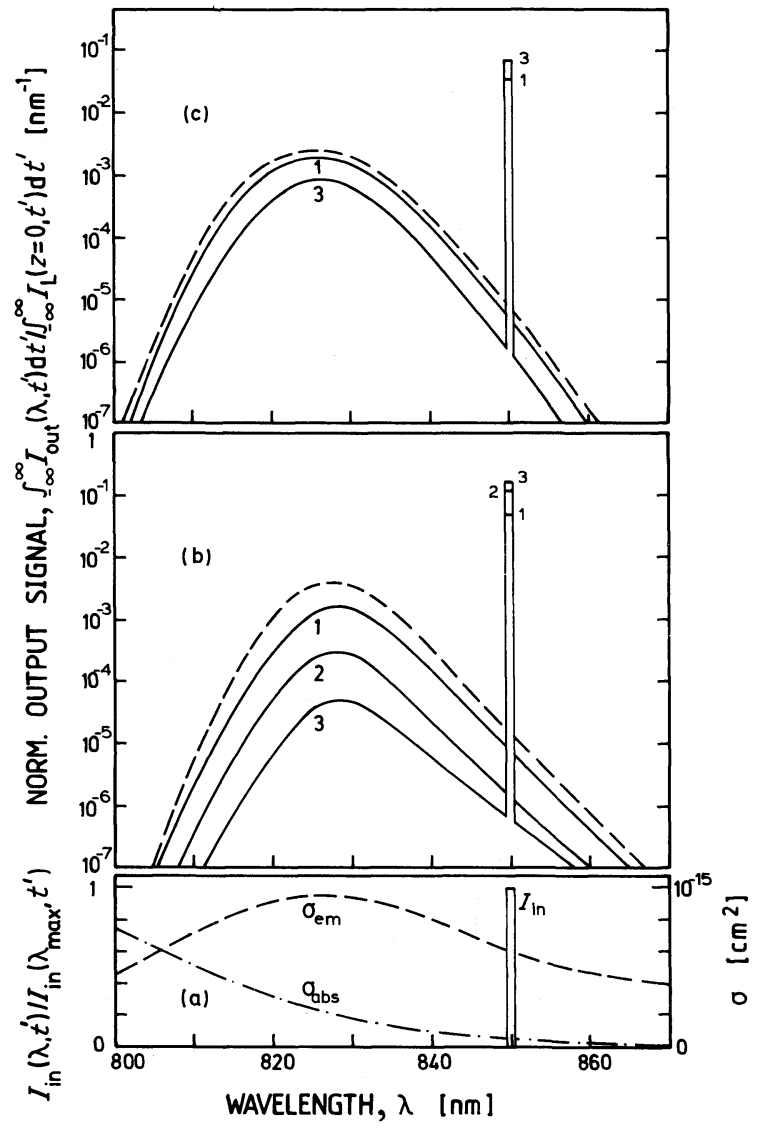

Figure 29 Spectral behaviour of narrowband light amplification in amplifier cell. For legend see Fig. 28. $\Delta \lambda=1 \mathrm{~nm}, \lambda=850 \mathrm{~nm}$.

generated light [38-40]. The self-focusing length $z_{\mathrm{f}}$ of the pump pulse is given by [41]

$$
z_{f}=(0.135)^{1 / 2} 2 \pi \tilde{v} a^{2}\left\{\left[\left(\frac{8 \pi^{2} a^{2} \tilde{v}^{2}}{3.72} \Delta n\right)^{1 / 2}-0.852\right]^{2}-0.0219\right\}^{-1 / 2}
$$

where $a$ is the $1 / e$ intensity radius of the pump pulse. $z_{\mathrm{f}}$ values for $I_{0 \mathrm{~L}}=5 \times 10^{9} \mathrm{~W} \mathrm{~cm}^{-2}$ and $\Delta n=\Delta n_{\mathrm{S}}+\Delta n_{\mathrm{D}}^{\max }\left(v_{\mathrm{L}}\right)$ are given in Table II (the $\Delta n_{\mathrm{S}}$ of ethylene glycol and of DMSO

TABLE II Refractive index changes and influence on pump pulse propagation. $\lambda_{\mathrm{L}}=694.3 \mathrm{~nm}, I_{0 \mathrm{~L}}=$ $5 \times 10^{9} \mathrm{~W} \mathrm{~cm}^{-2}, \Delta t_{\mathrm{L}}=30 \mathrm{ps}, a=0.48 \mathrm{~mm}$, non-linear refractive index of methanol, $n_{2}=2.2 \times 10^{-13}$ esu $=$ $3.1 \times 10^{-21} \mathrm{~m}^{2} \mathrm{~V}^{-2}[68,69] . n_{2}$ values of ethylene glycol and DMSO are not known. The refractive indices at $20^{\circ} \mathrm{C}$ and $\lambda_{\mathrm{D}}=589.3 \mathrm{~nm}$ are $n_{\mathrm{S}}=1.3284$ for methanol, $n_{\mathrm{S}}=1.4318$ for ethylene glycol and $n_{\mathrm{S}}=1.4770$ for DMSO [70]. The $\Delta n_{\mathrm{s}}$ value of methanol is used for all solvents

\begin{tabular}{|c|c|c|c|c|c|c|}
\hline Substance & $\begin{array}{l}\text { Concentration } \\
\text { (M) }\end{array}$ & $\Delta n_{\mathrm{S}}$ & $\Delta n_{\mathrm{D}}^{\max }$ & $\begin{array}{l}l_{\text {eff }} \\
(\mathrm{cm})\end{array}$ & $\begin{array}{l}z_{\mathrm{f}} \\
(\mathrm{cm})\end{array}$ & $\begin{array}{l}\Delta \tilde{v}_{\mathrm{br}} \\
\left(\mathrm{cm}^{-1}\right)\end{array}$ \\
\hline $\mathrm{DDI} / \mathrm{ME}$ & $10^{-4}$ & $4.3 \times 10^{-5}$ & $2.6 \times 10^{-4}$ & 0.33 & 1.4 & 3.2 \\
\hline Rh800/ME & $2 \times 10^{-3}$ & $4.3 \times 10^{-5}$ & $-6 \times 10^{-5}$ & 0.12 & 6.4 & 0.06 \\
\hline HITCI/ME & $7.7 \times 10^{-5}$ & $4.3 \times 10^{-5}$ & $1.6 \times 10^{-4}$ & 0.26 & 1.7 & 1.7 \\
\hline HDITCI/EG-DMSO & $5.1 \times 10^{-5}$ & & $7.2 \times 10^{-5}$ & 0.39 & 2.3 & 1.4 \\
\hline Styril 9/DMSO & $2.5 \times 10^{-4}$ & & $4.2 \times 10^{-5}$ & 0.17 & 2.7 & 1.3 \\
\hline IR $140 / E G-D M S O$ & $3.7 \times 10^{-5}$ & & $6.7 \times 10^{-5}$ & 0.39 & 2.4 & 0.45 \\
\hline Methanol & & $4.3 \times 10^{-5}$ & 0 & 1.0 & 3.8 & 1.4 \\
\hline
\end{tabular}




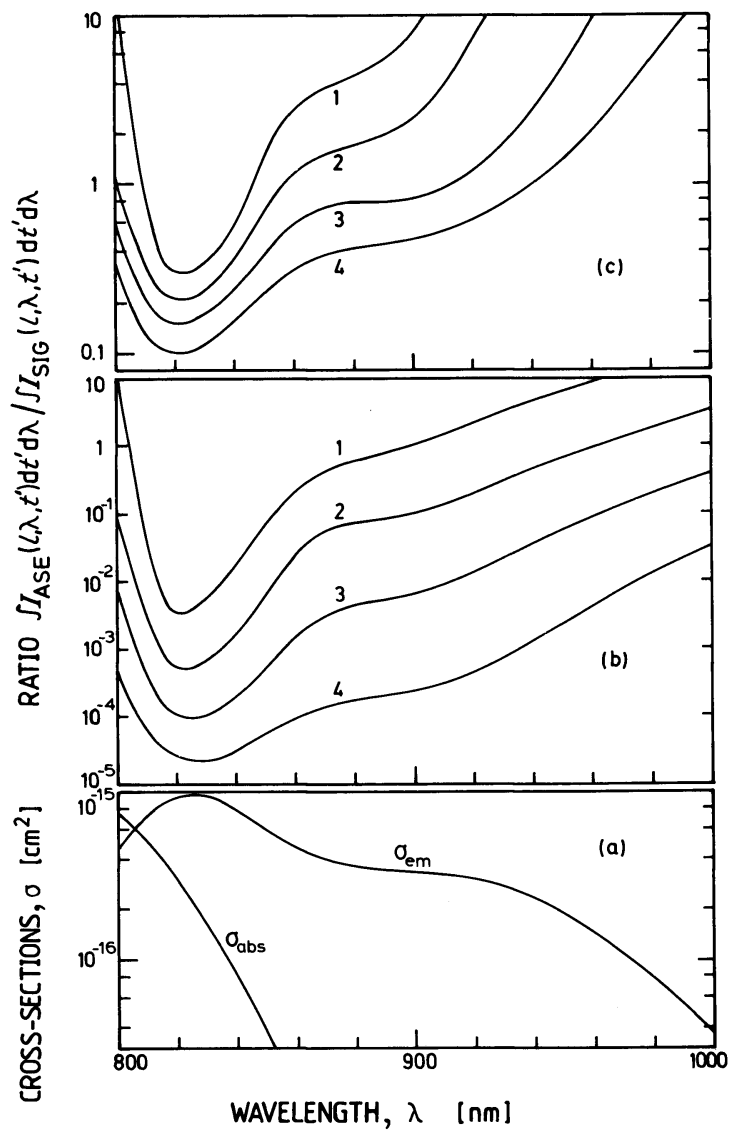

Figure 30 Dominance of narrow-band light amplification over ASE versus wavelength region. Dye is $5.1 \times 10^{-5} \mathrm{M} \mathrm{HDITCl}$ in $1: 1$ ethylene glycol-DMSO. Cell length $/=1 \mathrm{~cm}$, pump pulse diameter $d=0.8 \mathrm{~mm}$. Input pulse, temporal shape, see Fig. 26a; spectral shape, see Fig. 29a. $\Delta \lambda=1 \mathrm{~nm}$. (a) Cross sections $\sigma_{\mathrm{em}}(\lambda)$ and $\sigma_{\mathrm{abs}}(\lambda)$. (b) $I_{0 \mathrm{~L}}=3 \times$ $10^{8} \mathrm{~W} \mathrm{~cm}^{-2}$. (c) $I_{0 \mathrm{~L}}=6 \times 10^{9} \mathrm{~W} \mathrm{~cm}^{-2}$. (1) $I_{\text {in }, 0} / I_{\mathrm{OL}}=10^{-4},(2) I_{\text {in }, 0} / I_{0 \mathrm{~L}}=10^{-3}$, (3) $I_{\text {in }, 0} /$ $I_{\mathrm{OL}}=10^{-2}$, (4) $I_{\mathrm{in}, 0} / I_{\mathrm{OL}}=10^{-1}$.

are assumed to be equal to those of methanol). The $z_{\mathrm{f}}$ values have to be compared with the effective interaction lengths $l_{\mathrm{eff}}=\min \left(l, 1 / N_{0} \sigma_{\mathrm{ex}}^{\mathrm{L}}\right)$ (Table II). For all dyes investigated $z_{\mathrm{f}}>l_{\text {eff }}$ and therefore self-focusing does not influence drastically the light generation in the dye generator and amplifier cells.

Temporal changes of the refractive index lead to self-phase modulation [39-41]. The spectral broadening of the pump pulse due to self-phase modulation is given by [18]

$$
\Delta \tilde{v}_{\mathrm{br}} \approx \frac{2 \tilde{v}_{\mathrm{L}} l_{\mathrm{eff}}}{c_{0}} \frac{\Delta n}{\Delta t_{\mathrm{L}}}
$$

$\Delta n$ is given by Equation 33. Values of $\Delta \tilde{v}_{\mathrm{br}}$ are collected in Table II for the dyes investigated $\left(I_{0 \mathrm{~L}} \approx 5 \times 10^{9} \mathrm{~W} \mathrm{~cm}^{-2}\right.$ and $\left.\Delta n=\Delta n_{\mathrm{S}}+\Delta n_{\mathrm{D}}^{\max }\left(v_{\mathrm{L}}\right)\right)$. The broadening is small, and does not influence the ASE light generation and amplification (no seeding pulse formation). The ASE signal generated has a very short coherence length and its self-phase modulation is without importance.

\subsubsection{Resonance Raman amplification}

The ASE signal behind the generator is free of Raman lines in all experiments. In the seeding pulse amplification, Stokes Raman lines have been observed upon the amplified 

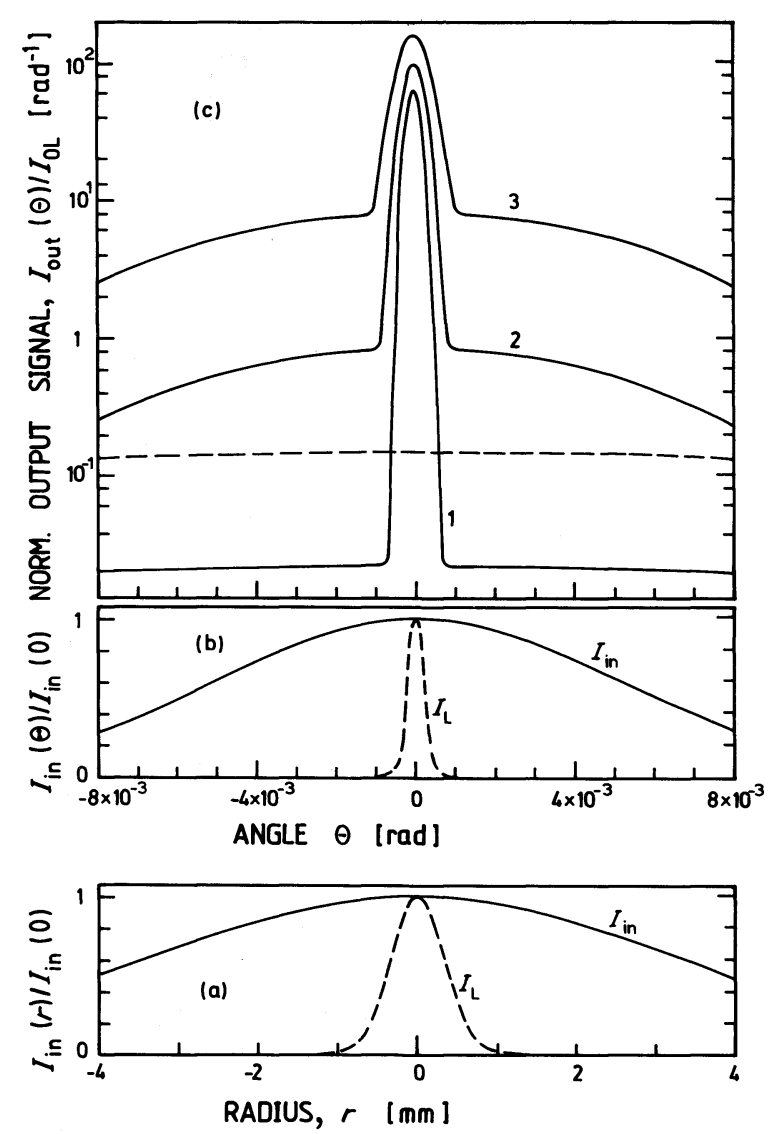

Figure 31 Angular distribution of light behind amplifier cell. Dye is $5.1 \times 10^{-5} \mathrm{M}$ HDITCl in $1: 1$ ethylene glycol-DMSO. Cell length $l=1 \mathrm{~cm}$. Temporal and spectral pulse shapes of pump pulse and input signal are identical to Fig. 26. (a) Spatial distributions. Broken curve, pump pulse; full curve, input signal. (b) Angular distributions. Broken curve, pump pulse; full curve, input signal. (c) Angular distribution of output signals for $I_{0 \mathrm{~L}}=10^{9} \mathrm{~W} \mathrm{~cm}^{-2}$. Broken curve, ASE signal (input signal peak intensity $l_{\text {in, } 0}=0$ ); full curves, (1) $l_{\text {in, } 0}=10^{5} \mathrm{~W} \mathrm{~cm}^{-2}$, (2) $l_{\text {in }, 0}=10^{7} \cdot \mathrm{W} \mathrm{cm}^{-2}$, (3) $l_{\text {in }, 0}=10^{8} \mathrm{~W} \mathrm{~cm}^{-2}$.

light continuum at high pump-pulse intensities for some dye solutions. Behind the amplifier cells the same Raman lines were found upon the amplified ASE signals.

The Raman gain is not large enough to show up in the amplification of spontaneous emission in the generator cell. The ASE signal reaches its maximum towards the end of the pump pulse. At the position of the pump pulse peak intensity, where the Raman amplification is highest, the ASE signal is still very weak. The amplification of this signal by Raman scattering is too small to be resolved in the spectrum. In the case of the seeding pulse amplification in the generator cell and of the ASE light amplification in the amplifier cells, the pump pulse maximum and the input signal maximum coincide. The light amplification by stimulated resonance Raman scattering is strong enough to be seen in the spectra for high pump-pulse intensities.

The detected Raman lines are listed in Table III. The frequency shifts belong to vibrational transitions of the dye molecules. The solvents methanol [72], ethylene glycol [73] and DMSO [74] have no vibrational transitions at the measured frequency shifts. The Raman transitions are resonantly enhanced by the $S_{0}-S_{1}$ absorption of the pump laser [43-47].

At the Raman Stokes frequency $v_{R}$ the simultaneous amplification of input light by stimulated emission and stimulated Raman scattering is given approximately by [48, 49]

$$
\frac{\partial I\left(v_{\mathrm{R}}\right)}{\partial z}=\sigma_{\mathrm{em}}\left(v_{\mathrm{R}}\right)\left(N_{3}-N_{6}\right) I\left(v_{\mathrm{R}}\right)+g_{\mathrm{S}} I_{\mathrm{L}} I\left(v_{\mathrm{R}}\right)
$$




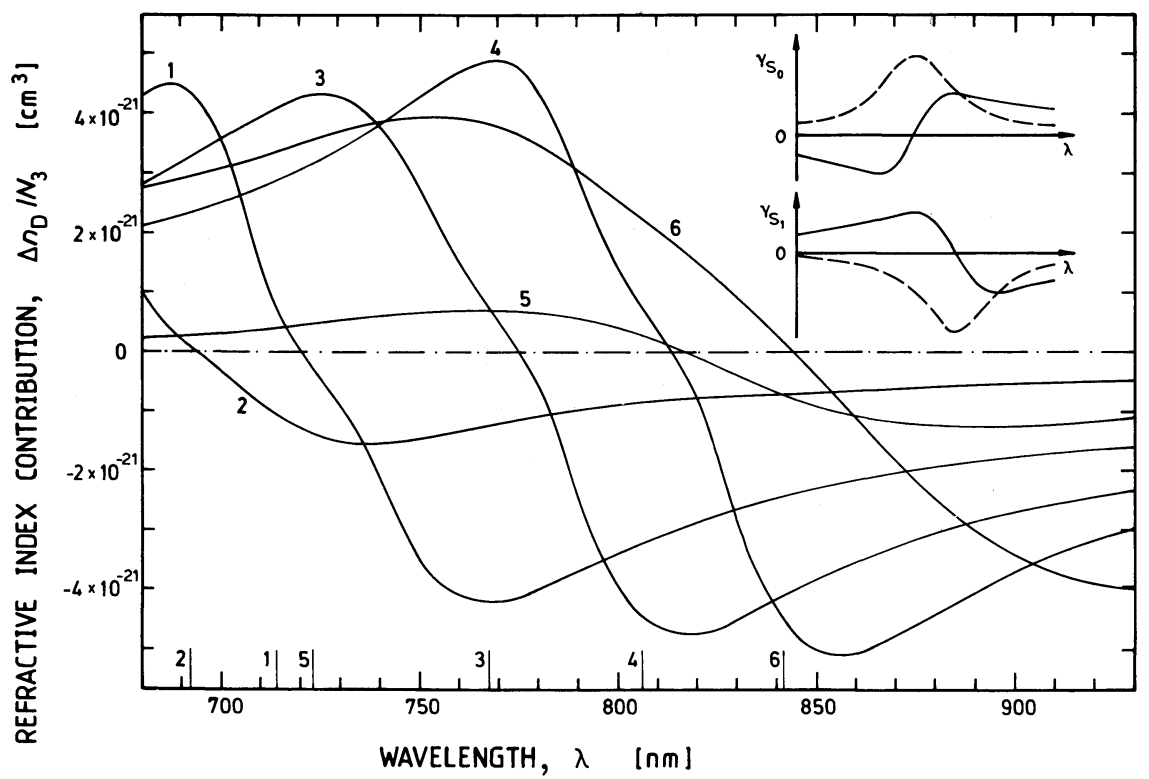

Figure 32 Refractive index change of completely bleached dyes compared to unexcited dyes. (1) $10^{-4} \mathrm{M} \mathrm{DDI}$ in methanol, (2) $2 \times 10^{-3} \mathrm{M}$ rhodamine 800 in methanol, (3) $7.7 \times 10^{-5} \mathrm{M} \mathrm{HITCl}$ in methanol, (4) $5.1 \times 10^{-5} \mathrm{M} \mathrm{HDITCl}$ in $1: 1$ ethylene glycol-DMSO, (5) $2.5 \times 10^{-4} \mathrm{M}$ styril 9 in DMSO, (6) $3.7 \times 10^{-5} \mathrm{M}$ IR 140 in 1:1 ethylene glycol-DMSO. Equation 33 is used for the calculation. The insets illustrate the wavelength dependences of the polarizabilities $\gamma_{s_{0}}=\gamma_{s_{0}}^{\prime}-i \gamma_{s_{0}}^{\prime \prime}$ and $\gamma_{s_{1}}=\gamma_{s_{1}}^{\prime}-i \gamma_{s_{0}}^{\prime \prime}$ (full curves, $\gamma^{\prime}$; broken curves, $\left.\gamma^{\prime \prime}\right)$. The vertical bars indicate the electronic $S_{0}-S_{1}$ transition frequencies $\lambda_{s_{1}}$.

TABLE III Raman data

\begin{tabular}{|c|c|c|c|c|c|}
\hline Substance & $\begin{array}{l}\text { Concentration, } C \\
\text { (M) }\end{array}$ & $\begin{array}{l}\text { Stokes } \\
\text { wavelength, } \\
\lambda_{\mathrm{R}} \\
(\mathrm{nm})\end{array}$ & $\begin{array}{l}\text { Frequency } \\
\text { shift, } \\
\tilde{v}_{\mathrm{L}}-\tilde{v}_{\mathrm{R}} \\
\left(\mathrm{cm}^{-1}\right)\end{array}$ & $\begin{array}{l}\text { Gain } \\
\text { factor, } \\
g_{\mathrm{S}} \\
\left(\mathrm{cm} \mathrm{W}^{-1}\right)\end{array}$ & $\begin{array}{l}\text { Molecular } \\
\text { gain factor, } \\
g_{\mathrm{S}} / N_{0} \\
\left(\mathrm{~cm}^{4} \mathrm{~W}^{-1}\right)\end{array}$ \\
\hline \multicolumn{6}{|l|}{ Dye solutions } \\
\hline $\mathrm{DDI} / \mathrm{ME}$ & $10^{-4}$ & $766 \pm 1$ & $1348 \pm 15$ & $3 \times 10^{-10}$ & $5 \times 10^{-27}$ \\
\hline \multirow[t]{3}{*}{ Rhodamine $800 / \mathrm{ME}$} & $2 \times 10^{-3}$ & $766 \pm 1$ & $1348 \pm 15$ & $1 \times 10^{-10}$ & $10^{-28}$ \\
\hline & & $776.5 \pm 1$ & $1525 \pm 15$ & $1 \times 10^{-10}$ & $10^{-28}$ \\
\hline & & $785.5 \pm 1$ & $1672 \pm 15$ & $3 \times 10^{-10}$ & $2.5 \times 10^{-28}$ \\
\hline \multirow[t]{4}{*}{ HDITCI/EG-DMSO } & $5.1 \times 10^{-5}$ & $857.5 \pm 1$ & $2741 \pm 15$ & $4 \times 10^{-10}$ & $10^{-26}$ \\
\hline & & $869 \pm 1$ & $2896 \pm 15$ & $<3 \times 10^{-11}$ & $<10^{-27}$ \\
\hline & & $878 \pm 3$ & $3013 \pm 40$ & $6 \times 10^{-11}$ & $2 \times 10^{-27}$ \\
\hline & & $888.5 \pm 1$ & $3148 \pm 15$ & $6 \times 10^{-11}$ & $2 \times 10^{-27}$ \\
\hline IR 140/EG-DMSO & $3.7 \times 10^{-5}$ & $889 \pm 1$ & $3154 \pm 15$ & & \\
\hline \multicolumn{6}{|l|}{ Solvent } \\
\hline Methanol & & 864.6 & 2837 & $4 \times 10^{-10}[71]$ & $2.7 \times 10^{-32}$ \\
\hline
\end{tabular}

The solution of Equation 36 is

$$
\begin{aligned}
I\left(v_{\mathrm{R}}, l\right) & =I\left(v_{\mathrm{R}}, 0\right) \exp \left[\sigma_{\mathrm{em}}\left(v_{\mathrm{R}}\right)\left(N_{3}-N_{6}\right) l+g_{\mathrm{S}} I_{\mathrm{L}} l\right] \\
& =I_{\mathrm{AMP}}\left(v_{\mathrm{R}}, l\right) \exp \left(g_{\mathrm{S}} I_{\mathrm{L}} l\right)
\end{aligned}
$$


$I\left(v_{\mathrm{R}}, 0\right)$ is the input signal. $I_{\mathrm{AMP}}\left(v_{\mathrm{R}}, l\right)$ is the output signal without Raman amplification. Estimated gain factors, $g_{\mathrm{s}}$, and molecular gain factors, $g_{\mathrm{s}} / N_{0}$, are listed in Table III. The $g_{\mathrm{s}}$-data are only accurate within a factor of 3 . For comparison the gain factor of the strongest Raman line of the solvent methanol is included in Table III. The resonance enhancement of the molecular gain factors is of the order of $10^{5}$.

\subsubsection{Coherence properties}

Light of spectral width $\Delta v$ has a coherence length of $l_{\text {coh }}=c_{0} / \Delta v=\Delta \tilde{v}^{-1}$ and a coherence time of $\tau_{\mathrm{coh}}=\Delta v^{-1}$ [50-53]. A light source of diameter $d$ emits coherently within a divergence angle $\Delta \Theta_{\text {coh }}=\lambda / d=(\tilde{v} d)^{-1}$. At a distance $R$ from the light source the coherence area is $\Delta A_{\text {coh }}=\left(R \Delta \Theta_{\text {coh }}\right)^{2}$ and the coherence volume is $\Delta V_{\text {coh }}=\Delta A_{\text {coh }} l_{\text {coh }}=\Delta A_{\text {coh }} c_{0} \tau_{\text {coh }}$. The degeneracy factor, $\delta_{\text {coh }}$, defines the number of photons within the coherence volume. For light of intensity $I$ the degeneracy factor is $\delta_{\text {coh }}=(I / h v) \Delta A_{\text {con }} \tau_{\text {coh }}$. For $\delta_{\text {coh }}<1$ no interference between photons occurs [50-53].

The spontaneous emission is characterized by $\delta_{\text {coh }}<1$. The emission follows Gaussian noise statistics $[50,51,54]$. Within the coherence angle temporal and spectral resolved fluorescence emission would reveal temporal and spectral fluctuations. Spectral integration over times $t$ that are long compared with $\tau_{\text {coh }}$ smoothes the spectrum. In the case of integration over a wide observation angle $\Delta \Theta \gg \Delta \Theta_{\text {coh }}$ the spectrally and temporally resolved distributions become smooth.

In the case of amplified spontaneous emission the degeneracy factor of the generated light is $\delta_{\text {coh }} \gg 1[50,51]$. The fluctuating spontaneous emission is coherently amplified. The output signal remains its Gaussian noise characteristics. The gain narrowing of the spectrum increases the coherence length compared with the spontaneous emission. For observation angles $\Delta \Theta^{\prime} \leqslant \Delta \Theta_{\text {coh }}$ the generated ASE spectra are strongly structured and the temporal ASE signals are strongly modulated (see Figs 20a and 21a) [55, 56]. For divergence angles $\Delta \Theta_{\mathrm{ASE}} \gg \Delta \Theta_{\text {coh }}$ and $\Delta \Theta^{\prime} \geqslant \Delta \Theta_{\mathrm{ASE}}$ the spectra and the temporal profiles are smooth (see Figs $20 \mathrm{~b}$ and $21 \mathrm{~b}$ ).

The picosecond light continua start from quantum fluctuations [18, 57-62]. They have similar coherence properties to the ASE light. The amplified seeding pulse spectra are strongly modulated $\left(\Delta \Theta_{\mathrm{SPA}} \approx \Delta \Theta_{\text {coh }}\right)$ and the temporal profiles are structured (see Figs 5 and 6 of [10]). The coherence properties of stimulated Raman scattering have been investigated recently [63-65].

\section{Conclusions}

In picosecond laser pumped dye laser generators and amplifiers intense frequency tunable picosecond light pulses may be generated. In the described experiments frequency tunable picosecond pulses in the spectral range between 720 and $940 \mathrm{~nm}$ have been generated by amplified spontaneous emission and seeding pulse amplification with a picosecond ruby laser. The spectral range may be extended to a wider spectral region by using other picosecond laser pump sources and dyes. Laser dyes with high fluorescence quantum efficiency $q_{\mathrm{F}}$ as well as saturable absorbers with low fluorescence quantum efficiency are suitable as active media (no gain reduction as long as $\tau_{\mathrm{F}}>\Delta t_{\mathrm{L}}$ ).

\section{Acknowledgements}

The authors thank Th. Ascherl for technical assistance. They thank the Deutsche Forschungsgemeinschaft for financial support and the Rechenzentrum of the University for the allocation of computer time. 


\section{References}

1. C. V. SHANK and E. P. IPPEN, in 'Dye Lasers', Topics in Applied Physics, Vol. 1, edited by F. P. Schäfer (Springer-Verlag, Berlin, 1977) p. 121.

2. D. J. BRADLEY, in 'Ultrashort Light Pulses', Topics in Applied Physics, Vol. 18, edited by S. L. Shapiro (Springer-Verlag, Berlin, 1977) p. 18.

3. G. R. FLEMING, 'Chemical Applications of Ultrafast Spectroscopy' (Oxford University Press, New York, 1986) p. 5.

4. ZS. BOR and A. MÜLLER, IEEE J. Quantum Electron. QE-22 (1986) 1524.

5. H. J. POlland, T. ElSAESSER, A. SEILMEIER and W. KAISER, Appl. Phys. B32 (1983) 53.

6. ZS. BOR, S. SZATMARI and A. MÜLLER, ibid. B32 (1983) 101.

7. S. SZATMARI and F. P. SCHÄFER, Opt. Commun. 49 (1984) 281.

8. T. ELSAESSER, H. J. POLLAND, A. SEILMEIER and W. KAISER, IEEE J. Quantum Electron. QE-20 (1984) 191.

9. W. LEE, C. NING and Z. HUANG, Appl. Phys. B40 (1986) 35.

10. P. SPERBER, M. WEIDNER and A. PENZKOFER, ibid. B42 (1987) 185.

11. A. SEILMEIER and W. KAISER, ibid. 23 (1980) 113.

12. W. KAISER and A. SEILMEIER, Infrared Phys. 25 (1985) 15.

13. R. DANELYUS, G. DIKCHYUS, V. KABELKA, A. PISKARSKAS, A. STABINIS and YA. YASERVICHYUTE, Soviet J. Quantum. Electron. 7 (1977) 1360.

14. I. N. DUling, T. NORRIS, T. SIZER, P. BADO and G. MOUROU, J. Opt. Soc. Am. B2 (1985) 616.

15. R. L. FORK, B. I. GREENE and C. V. SHANK, Appl. Phys. Lett. 38 (1981) 671.

16. D. B. McDONALD and C. D. JONAH, Rev. Scient. Instrum. 55 (1984) 1166.

17. M. E. MACK, Appl. Phys. Lett. 15 (1969) 166.

18. A. PENZKOFER and W. KAISER, Opt. Quantum Electron. 9 (1977) 315.

19. A. MIGUS, J. L. MARTIN, R. ASTIER, A. ANTONETTI and A. ORIZAG, in 'Picosecond Phenomena III', Springer Series in Chemical Physics, Vol. 23, edited by K. B. Eisenthal, R. M. Hochstrasser, W. Kaiser and A. Laubereau (Springer-Verlag, Berlin, 1982) p. 6.

20. Y. K. PARK, G. GIULIANI and R. L. BYER, Opt. Lett. 5 (1980) 96.

21. Y. LU and A. PENZKOFER, Chem. Phys. 107 (1986) 175.

22. O. G. PETERSON, J. P. WebB, W. C. McColgin and J. H. EBerly, J. Appl. Phys. 42 (1971) 1917.

23. A. PENZKOFER and W. LEUPACHER, J. Luminescence 37 (1987) 61.

24. S. J. STRICKLER and R. A. BERG, J. Chem. Phys. 37 (1962) 814.

25. J. B. BIRKS and D. J. DYSON, Proc. R. Soc. A275 (1963) 135.

26. A. PENZKOFER and W. BLAU, Opt. Quantum Electron. 15 (1983) 325.

27. W. BlaU, W. DANKeSREITER and A. PENZKOFER, Chem. Phys. 85 (1984) 473.

28. A. PENZKOFER and P. SPERBER, Chem. Phys. 88 (1984) 309.

29. W. BlAU, R. REBER and A. PENZKOFER, Opt. Commun. 43 (1982) 210.

30. A. PENZKOFER, Opto-Electronics 6 (1974) 87.

31. W. BLAU and A. PENZKOFER, Opt. Commun. 36 (1981) 419.

32. A. PENZKOFER, Appl. Phys. B40 (1986) 85.

33. A. PENZKOFER and W. FALKENSTEIN, Opt. Quantum Electron. 10 (1978) 399.

34. A. G. FOX and T. LI, Bell Syst. Tech. J. 40 (1961) 453.

35. M. BORN and E. WOLF, 'Principles of Optics', 6th Edn (Pergamon Press, London, 1980) p. 375.

36. Y. LU and A. PENZKOFER, Appl. Opt. 25 (1986) 221.

37. M. SCHUBERT and B. WILHELMI, 'Nonlinear Optics and Quantum Electronics' (Wiley, New York, 1986) p. 205.

38. P. L. KELley, Phys. Rev. Lett. 15 (1965) 1005.

39. S. A. AKHMANOV, R. V. KOKHLOV and A. P. SUKHORUKOV, in 'Laser Handbook', edited by F. T. Arecchi and E. O. Schultz-Dubois (North-Holland, Amsterdam, 1972) p. 1151.

40. A. N. RUbinov, B. A. BUShUK, A. A. MURAV'OV and A. P. STUPAK, Appl. Phys. B30 (1983) 99.

41. J. M. MARBURGER, Prog. Quantum Electron. 4 (1975) 35.

42. F. SHIMIZU, Phys. Rev. Lett. 19 (1967) 1097.

43. A. LAU, K. LENZ, P. KiRCheVA, H. J. WeIGMANN, M. PFEIFFER and W. WERnCKe, Soviet J. Quantum Electron. 9 (1979) 1551.

44. H. FABIAN, A. LAU, W. WERNCKE, M. PFEIFFER, K. LENZ and H. J. WEIGMANN, ibid. 9 (1979) 40.

45. YA. S. BOBOVICH and A. V. BORTKEVICH, Opt. Spectrosc. (USSR) 26 (1969) 578. 
46. E. N. KESKINOVA and P. P. KIRCHEVA, Opt. Quantum Electron. 12 (1980) 315.

47. M. PFEIFFER, A. LAU and W. WERNCKE, J. Raman Spectrosc. 15 (1984) 20.

48. W. KAISER and M. MAIER, in 'Laser Handbook', Vol. 2, edited by F. T. Arecchi and E. O. Schultz-Dubois (North-Holland, Amsterdam, 1972) Ch. E2.

49. A. PENZKOFER, A. LAUBereau and W. KAISER, Prog. Quantum Electron. 6 (1979) 55.

50. L. MANDEL and E. WOLF, Rev. Mod. Phys. 37 (1965) 231.

51. R. J. GLAUBER, in 'Laser Handbook', Vol. 1, edited by F. T. Arecchi and E. O. Schulz-Dubois (NorthHolland, Amsterdam, 1972) Ch. Al.

52. Idem, Phys. Rev. 131 (1963) 2766.

53. J. PERINA, 'Coherence of Light' (Reidel, Dordrecht, 1985).

54. A. A. GRÜTTER, H. P. WEBER and R. DÄNDliker, Phys. Rev. 185 (1969) 629.

55. I. L. KLYUKACH and R. I. SOKOLOVSKII, Soviet Phys. JETP 44 (1976) 223.

56. L. D. DERKACHEVA and V. A. PETUKHOV, Opt. Spectrosc. (USSR) 45 (1978) 754.

57. R. L. BYER and S. E. HARRIS, Phys. Rev. 168 (1968) 1064.

58. T. G. GIALLORENZI and C. L. TANG, ibid. 166 (1968) 225

59. J. E. PEARSON, U. GANIEL and A. YARIV, Appl. Opt. 12 (1973) 1165.

60. J. P. GORDON, W. H. LOUISELl and L. R. WALKER, Phys. Rev. 129 (1963) 481.

61. Y. R. SHEN, ibid. 155 (1967) 921.

62. W. H. LOUISELL, 'Quantum Statistical Properties of Radiation' (Wiley, New York, 1973).

63. M. G. RAYMER, I. A. WALMSLEY, J. MOSTOWSKI and B. SOBOLEWSKA, Phys. Rev. A32 (1985) 332.

64. I. A. WALMSLEY and M. G. RAYMER, ibid. A33 (1986) 382.

65. M. G. RAYMER, Photonic Spectra 21(4) (1987) 167.

66. A. PENZKOFER, W. FALKENSTEIN and W. KAISER, Chem. Phys. Lett. 44 (1976) 82.

67. D. RICARD and J. DUCUING, J. Chem. Phys. 62 (1975) 3616.

68. P. P. HO and R. R. AlfANO, Phys. Rev. A20 (1979) 2170.

69. W. L. SMITH, in 'CRC Handbook of Laser Science and Technology', Vol. III, 'Optical Materials', Part 1: 'Nonlinear Optical Properties/Radiation Damage', edited by M. J. Weber (CRC Press, Boca Raton, Florida, 1986) p. 259.

70. R. C. WEAST, editor, 'CRC Handbook of Chemical Physics', 61st Edn (CRC Press, Boca Raton, Florida, 1980).

71. I. REINHOLD and M. MAIER, Opt. Commun. 5 (1972) 31.

72. J. P. STREMMAN and K. NAKAMOTO, 'Laboratory Raman Spectroscopy' (Wiley, New York, 1984$)$ p. 118.

73. K. W. F. KOHLRAUSCH, 'Ramanspektren' (Heyden, New York, 1972) p. 221.

74. F. R. DOLLISH, W. G. FATELEY and F. F. BENLLEY, 'Characteristic Raman Frequencies of Organic Compounds' (Wiley, New York, 1974) p. 324. 